\title{
A Remotely Sensed Assessment of Surface Ecological Change over the Gomishan Wetland, Iran
}

\author{
Salman Qureshi ${ }^{1}\left(\right.$, Seyed Kazem Alavipanah ${ }^{2, *}$, Maria Konyushkova ${ }^{3}\left({ }^{\circledR}\right.$, Naeim Mijani $^{2}{ }^{\circledR}$, \\ Solmaz Fathololomi ${ }^{4}$, Mohammad Karimi Firozjaei ${ }^{2}{ }^{(\mathbb{D}}$, Mehdi Homaee ${ }^{5}{ }^{(\mathbb{D}}$, Saeid Hamzeh ${ }^{2}$ and \\ Ata Abdollahi Kakroodi ${ }^{2}$ \\ 1 Institute of Geography, Humboldt University of Berlin, Rudower Chaussee 16, 12489 Berlin, Germany; \\ salman.qureshi@geo.hu-berlin.de \\ 2 Department of Remote Sensing and GIS, Faculty of Geography, University of Tehran, \\ Tehran 14178-53933, Iran; naeim.mijani@ut.ac.ir (N.M.); mohammad.karimi.f@ut.ac.ir (M.K.F.); \\ saeid.hamzeh@ut.ac.ir (S.H.); a.a.kakroodi@ut.ac.ir (A.A.K.) \\ 3 Department of Soil Geography, Lomonosov Moscow State University, 119991 Moscow, Russia; \\ mkon@inbox.ru \\ 4 Faculty of Agriculture and Natural Resources, University of Mohaghegh Ardabili, Ardabil 56199-13131, Iran; \\ fathis@uma.ac.ir \\ 5 Department of Irrigation and Drainage, Tarbiat Modares University, Tehran 14115-336, Iran; \\ mhomaee@modares.ac.ir \\ * Correspondence: salavipa@ut.ac.ir
}

Received: 18 July 2020; Accepted: 10 September 2020; Published: 14 September 2020

Abstract: Due to the excessive use of natural resources in the contemporary world, the importance of ecological and environmental condition modeling has increased. Wetlands and cities represent the natural and artificial strategic areas that affect ecosystem conditions. Changes in the ecological conditions of these areas have a great impact on the conditions of the global ecosystem. Therefore, modeling spatiotemporal variations of the ecological conditions in these areas is critical. This study was aimed at comparing degrees of variation among surface ecological conditions due to natural and unnatural factors. Consequently, the surface ecological conditions of Gomishan city and Gomishan wetland in Iran were modeled for a period of 30 years, and the spatiotemporal variations were evaluated and compared with each other. To this end, 20 Landsat 5, 7, and 8, and 432 Moderate Resolution Imaging Spectroradiometer (MODIS), monthly land surface temperature (LST) (MOD11C3) and normalized difference vegetation index (NDVI) (MOD13C3) products were utilized. The surface ecological conditions were modeled according to the Remote Sensing-based Ecological Index (RSEI), and the spatiotemporal variation of the RSEI values in the study area (Gomishan city, Gomishan wetland) were evaluated and compared with each other. According to MODIS products, the mean of the LST and NDVI variance values for the study area (Gomishan city, Gomishan wetland) were obtained to be $6.5^{\circ} \mathrm{C}(2.1,12.1)$ and $0.009(0.005,0.013)$, respectively. The highest LST and NDVI temporal variations were found for Gomishan wetland near the Caspian Sea. According to Landsat images, Gomishan wetland and Gomishan city have the highest and lowest temporal variations in surface biophysical characteristics, respectively. The mean RSEI for the study area (Gomishan city, Gomishan wetland) was $0.43(0.65,0.29)$, respectively. Additionally, the mean Coefficient of Variation (CV) of RSEI for the study area (Gomishan city, Gomishan wetland) was $0.10(0.88,0.51)$, respectively. The surface ecological conditions of Gomishan city were worse than those of the Gomishan wetland at all dates. Temporal variations in the surface ecological conditions of Gomishan wetland were greater than those of the study area and Gomishan city. These results can provide useful and effective information for environmental planning and decision-making to improve ecological conditions, protect the environment, and support sustainable ecosystem development. 
Keywords: urban ecosystem; urban ecology; wetlands; spatiotemporal variations; Landsat images; MODIS products

\section{Introduction}

Due to the excessive use of natural resources in the contemporary world, it is critical to model surface ecological and environmental conditions with the appropriate spatial and temporal resolution [1-5]. Regions that play important roles in ecosystems and habitat conservation can be considered ecological regions. These spaces include a set of artificial, semi-artificial and natural ecological units [6]. Wetlands and cities are the natural and artificial ecological areas that have the greatest effect on ecosystem conditions. Therefore, modeling the spatiotemporal variation of surface ecological conditions in these areas is of great importance [7-10].

Typically, the analysis of the spatiotemporal evolution trends and ecological sensitivity is performed based on terrestrial studies that are time-consuming, laborious, and costly. Additionally, the use of these methods is not effective for inaccessible areas. Moreover, the maps created by terrestrial surveys are usually less accurate and contain fewer spatial details, making it impossible to describe the spatiotemporal changes of ecological characteristics accurately [11].

Recent advances in satellite-based terrestrial observational systems have the potential to provide powerful ecosystem management tools that can provide valuable information regarding the status of ecosystems on a local to global scale [12-15]. Satellite data are capable of estimating the various characteristics of the Earth's surface; therefore, they can identify a wide range of ecological components $[16,17]$. Access to near-real-time and open-source satellite data, an increase in different temporal, spatial and spectral resolutions, and recent advances in processing large amounts of satellite data increase the efficiency of remote sensing data in ecosystem and environmental monitoring [18-20].

Different satellite image-based ecological indices play an important role in mapping and quantifying ecosystem characteristics. Among these indices, the normalized difference vegetation index (NDVI) and land surface temperature (LST) are the most common [21-24]. Because single satellite-based parameters, which are often used, show only one aspect of the ecological situation, they are not sufficient to reflect the extent and spatiotemporal characteristics of ecological quality change comprehensively [25-27]. Some studies have shown that a combination of several satellite-based indices can model spatiotemporal changes in surface ecological conditions more accurately [27-29]. Surface ecological conditions are one of the key factors in the improvement of ecosystem structure and performance and the maintenance of ecosystem characteristics and services [30-32].

Thus, in recent years, various studies have used satellite data to monitor, model, and recognize the factors that affect surface ecological conditions and their spatiotemporal patterns. $\mathrm{Xu}$, Wang, Shi, Guan, Fang and Lin [26] examined the impact of various characteristics, including land cover, population growth, and urban development on the surface ecological conditions of the Xiong'an region in northern China. In this study, the remote sensing-based ecological index (RSEI), which was based on the combination of four satellite-derived indices (i.e., NDVI, normalized difference salinity index (NDSI), wetness, and LST) were used to assess the surface ecological conditions. The results showed that urban physical expansion and population growth led to an increase in impervious surface cover (ISC), which has a significant negative impact on regional surface ecological conditions. Hu and Xu [15] modeled the spatial heterogeneity of surface ecological conditions in Fuzhou, China, between 2000 and 2016. In this study, the RSEI was used to evaluate the surface ecological conditions. The results showed that the urban physical growth led to the destruction of surface ecological conditions, and urban afforestation increased the ecological quality in the center of the urban area. Shan, et al. [33] evaluated the quality of ecological conditions in Changde city using Ecological Index (EI) and RSEI. The results showed that the RSEI was more effective at monitoring changing conditions than EI. Land surface moisture (LSM) and NDVI had a positive effect on improving the quality of ecological conditions, 
while LST and normalized differential build-up and bare soil index (NDBSI) had a negative effect. The effect of the NDBSI was more significant than other indices. Yang, et al. [34] assessed the impact of urbanization and human activities on spatiotemporal changes in the ecological conditions of Guangdong Bay in China. In this study, a Comprehensive Ecological Evaluation Index (CEEI) was used to describe the ecological conditions of the LST. The results showed that the ecological conditions quality during the period of 1987 to $2017 \mathrm{had}$ an increasing trend at first and then a decreasing trend. Poor quality ecological areas gradually shifted from the suburbs to urban areas. Chen, et al. [35] modeled the quality variation of surface ecological conditions in the pearl river delta, China. Examination of surface ecological conditions in the central pearl river delta showed a significant downward trend, while coastal cities showed an upward trend. There was also a negative correlation between the surface ecological conditions quality and urbanization indices. Yue, Liu, $\mathrm{Li}$ and $\mathrm{Lu}[25]$ investigated the ecological quality of China's 35 Major Cities based on the remote sensing data and RSEI. Their findings showed that between 1990 and 2015, the quality of ecological conditions in 18 cities in eastern and southwestern China deteriorated, and the ecological conditions of 17 cities in the north and central area of China was improved. Shen, et al. [36] analyzed the changes in the ecological degradation of the Zoige Plateau Wetland in China from 2000 to 2015 based on the satellite images and analytic hierarchy process (AHP). Their results showed that the most severe ecological degradation of the wetland was in 2005. They further reported that the spatial pattern of wetland degradation was from the northeast to the southwest over the 2000-2015 period. Firozjaei, Fathololoumi, Weng, Kiavarz and Alavipanah [14] assessed the ecological status of U.S.A. cities. The surface ecological conditions of different cities were calculated and evaluated using Remotely Sensed Urban Surface Ecological Index (RSUSEI) by combining the indices obtained from remote sensing data including LST, NDVI, NDSI, wetness and ISC using principle component analysis (PCA). Their results indicated that the highest and lowest values of RSUSEI were in "Developed, High intensity" and "Developed, Open Space" lands, respectively. Increasing the impervious surface causes reduced moisture and vegetation cover density and increases the surface heat and dryness and as a result, worsening the surface ecological conditions.

Eid, et al. [37] evaluated the status of various components including vegetation cover, water body and soil of Wadi El-Rayan Wetland, Egypt using Landsat images and remote sensing indices (Soil adjusted vegetation index ((SAVI), NDVI, enhanced vegetation index (EVI) and normalized difference water index (NDWI)). The results showed that the condition of the wetland has deteriorated over the past three decades. Rapinel, et al. [38] mapped and monitored wetlands condition on the Couesnon watershed, located in northeastern Brittany, France, using LiDAR, Sentinel-1/2 and Moderate Resolution Imaging Spectroradiometer (MODIS) time-series data. The results showed that $44 \%$ of the existing wetlands have been destroyed. Singh, et al. [39] analyzed spatial and temporal changes of land use/land cover (LULC), and water quality parameters in the Harike wetland ecosystem, Punjab, India, by using remote sensing data. The results revealed that intense cultivation and declining groundwater levels due to human activities in the region have a negative effect on the wetland. Orimoloye, et al. [40] evaluated the Isimangaliso Wetland, South Africa, using Landsat imagery. The result showed that the wetland features experienced drastic decreases between 1987 and 2017. Overall, these results indicate that changes in vegetation cover and water body significantly reduced the area and worsened the status of the Isimangaliso Wetland between 1987 and 2017. Alavipanah, et al. [41] investigated the spatial and temporal changes of LST and surface biophysical characteristics of Gomishan region, Iran during the period 1987-2017. The results of their study showed high spatial and temporal changes in the surface characteristics of Gomishan region and high efficiency of remote sensing data sets to quantify these changes.

A review of previous studies shows that the quality of surface ecological conditions and their variations in a region have a complex structure and mechanism and are influenced by several direct and indirect factors, such as land cover, surface biophysical characteristics, and anthropogenic activities. Past studies have focused on modeling the impact of human activity, including urban physical expansion, on the spatiotemporal changes in surface ecological conditions. However, natural changes 
in the environment, including the back and forth movement of seawater and wetlands, can also have a significant impact on the ecological conditions of an area.

The objective of this study was to compare the degree of variation in the surface ecological conditions due to both natural and unnatural factors. To this end, the surface ecological conditions of Gomishan city and the Gomishan wetland were modeled for a period of 30 years based on MODIS time series products and Landsat imagery, and the spatiotemporal changes were evaluated and compared.

\section{Study Area}

The study area includes the wetland and the city of Gomishan and their suburbs. The study area covers $3522 \mathrm{~km}^{2}$ and is located at 53.70 to 54.31 degrees east and 36.9 to 37.50 degrees north. According to the Emberger method [42], the climate of the study area is temperate semi-arid and the mean annual rainfall in the region is less than $250 \mathrm{~mm}$. The mean annual temperature is $17.6{ }^{\circ} \mathrm{C}$. With an average of $12 \mathrm{~mm}$, precipitation is the lowest in June and highest in March, when it averages $56 \mathrm{~mm}$. The city of Gomishan, with a $6 \mathrm{Km}^{2}$ area and a 20,000 population, is located in the southwest of the study area (Figure 1). The city's growth rate for the last 30 years was $1.1 \%$ per year. Due to the effect of geographical location and climatic conditions on the ecological conditions of the surface, the city of Gomishan with almost the same conditions as Gomishan wetland in terms of geographical location and climatic conditions was selected for this study. The Gomishan International Wetland, with an area of $177 \mathrm{Km}^{2}$, is the most important environmental feature in this region. The wetland water depth varies and depends on changes in the Caspian Sea water level. Despite this fluctuation, the Gomishan wetland depth is more than one meter (mean depth is $1.5 \mathrm{~m}$ ) in most parts. Various studies have shown that changes in water level and environmental and ecological characteristics of this wetland are very high [43]. The wetland has a north-south longitudinal extension that is bounded by the Gorgan River in the south, by the Atrak River in the north, and by a strip of sand dunes in the west that separates it from the Caspian Sea.

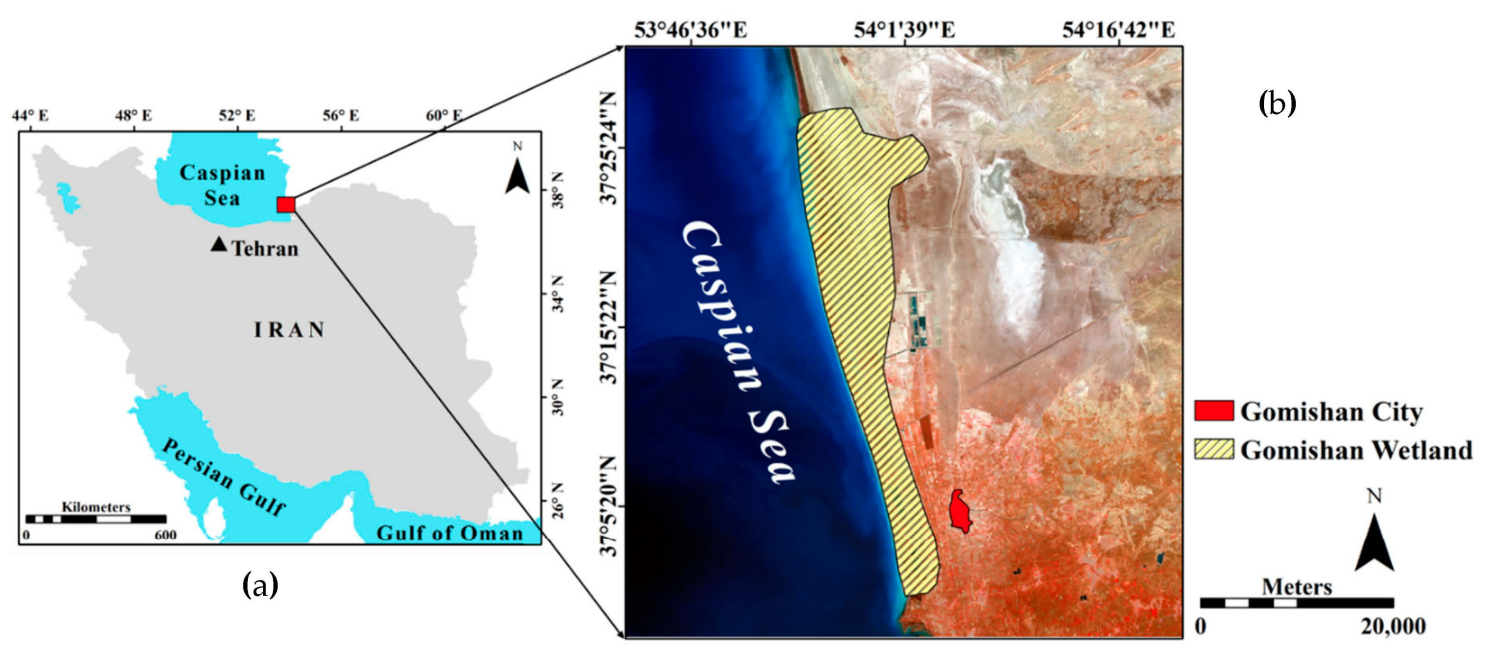

Figure 1. The study area geographical location in Iran (a), and the false color composite image of the Landsat 8 Operational Land Imager (OLI) (Near infrared, Red and Green bands) for 15/05/2017 of the studied area and the location of the of Gomishan wetland and city in the study area (b).

The eastern and northeastern regions of the wetland are affected by arid and semi-arid climates due to the vast expanse of flat lands, lack of heights, distance from the southern forests, and proximity to the Turkmen deserts. Moving from the south to the border, the intensity of this type of climate increases. The study area geographical location is shown in Figure 1. 


\section{Data and Methods}

\subsection{Data}

In this study, MODIS products and Landsat images were used (Table 1). Landsat 5, 7, and 8 images, including Level 1 Terrain (Corrected) (L1T), were used with WRS_PATH = 164 and WRS_ROW $=035$. These imagery are available on the https://www.usgs.gov/. Landsat imagery was selected in such a way that (1) the maximum cloud cover of the study area at satellite overpass time was a maximum of $10 \%$ and (2) their dates were close enough to each other so that seasonal changes did not affect the results of various analyses. The range of Day of Year (DOY) values of used Landsat images was less than 60 days. These images have the appropriate resolution to highlight the trend and surface coverage features.

Table 1. Data layers used in this study details. TM: Thematic Mapper; TIRS: Thermal Infrared Sensor; ETM+: Enhanced Thematic Mapper Plus (ETM+); LAADS: Atmosphere Archive and Distribution System; USGS: United States Geological Survey.

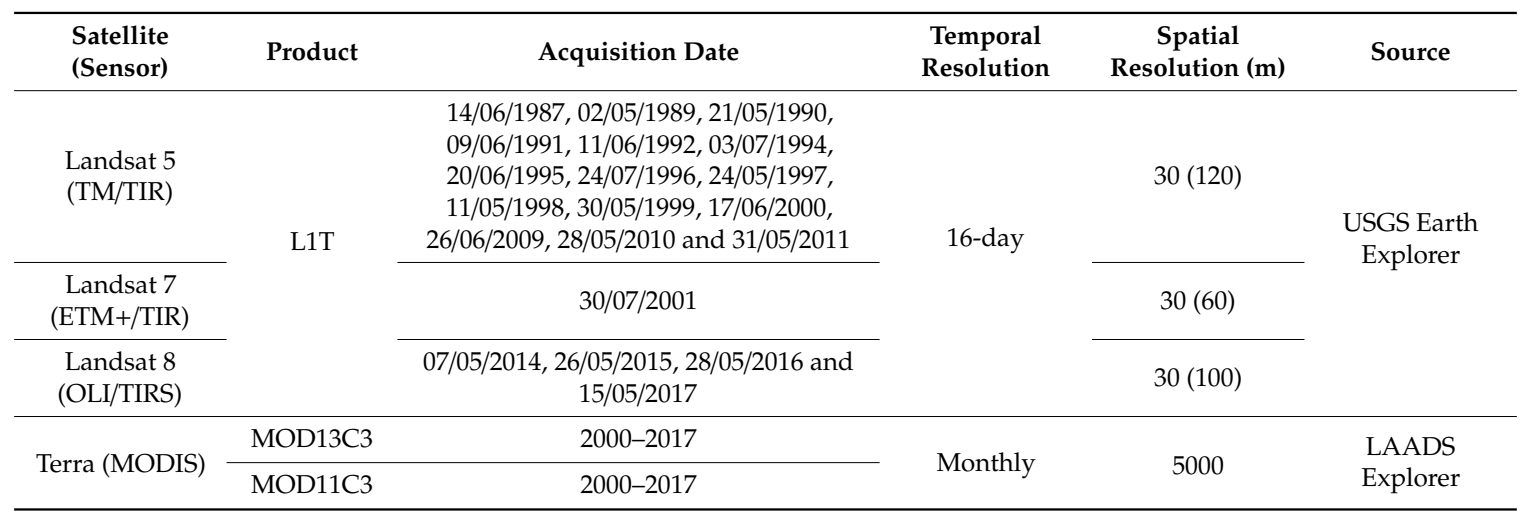

In addition to Landstat data, monthly LST (MOD11C3) and NDVI (MOD13C2) MODIS/Terra products were used every month from the beginning of 2000 to the end of 2017. The spatial resolution of these products is $5000 \mathrm{~m}$. MODIS products were downloaded from https://lpdaac.usgs.gov/.

\subsection{Methods}

The complete steps of this research are shown in Figure 2. In the first step, the trend of LST and NDVI spatiotemporal variations of the study area (Gomishan city, Gomishan wetland) from 2000 to 2017 were evaluated and compared using the monthly MODIS products. In the second step, spectral indices and methods were implemented to model the biophysical characteristics after pre-processing the Landsat imagery. Then, spatiotemporal variations of the Landsat-derived biophysical characteristics for the study area (Gomishan wetland and Gomishan city) were evaluated and compared with each other. In the third step, the land cover of the study area was classified using Landsat images. Then, the spatiotemporal changes of the different land covers were examined. In the fourth step, the main surface characteristics, including heat, greenness, dryness, and wetness, were combined based on RSEI, and surface ecological conditions were modeled using Landsat imagery. Then, the spatiotemporal variations for the study area (Gomishan wetland and Gomishan city) were evaluated and compared with each other. 


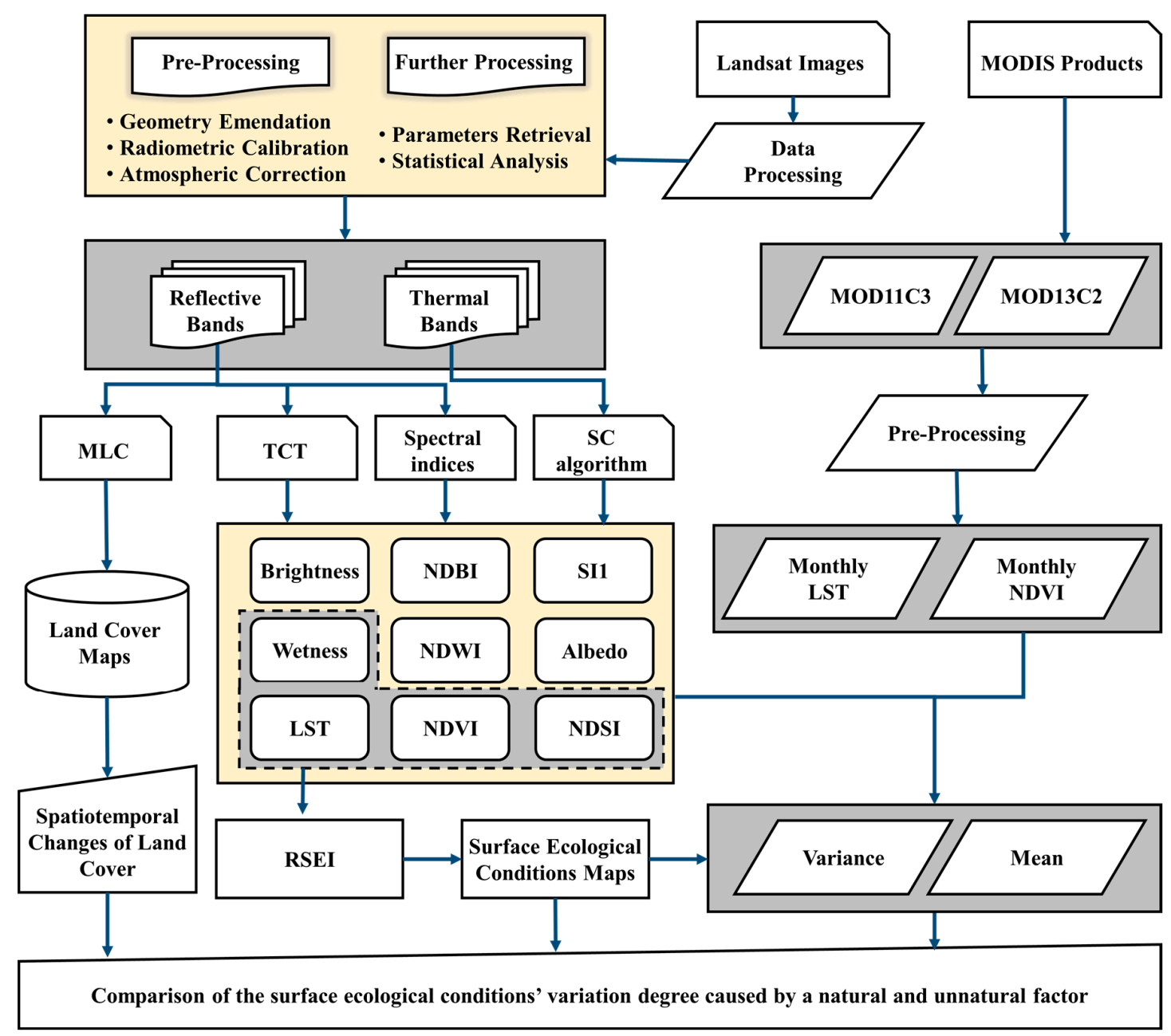

Figure 2. Conceptual framework and flow of the study. Note: MLC: Maximum Likelihood Classification; TCT: Tasseled Cap Transformation; SC: Single-Channel; NDBI: Normalized Difference Built-up Index; SI1: Salinity Index 1; NDWI: Normalized Difference Water Index; LST: Land Surface Temperature; NDVI: Normalized Difference Vegetation Index; NDSI: Normalized Difference Salinity Index; RSEI: Remote Sensing-based Ecological Index.

\subsubsection{Spatiotemporal Changes of LST and NDVI Using MODIS Products}

In this study, the trend of LST and NDVI spatiotemporal variations in the study area was investigated using MODIS monthly LST and NDVI products. For this purpose, the temporal variations of the mean LST and NDVI in the study area for each month during the period from 2000 to 2017 were calculated and evaluated. The temporal variations of the mean LST for the study area, Gomishan city and the Gomishan wetland in different months were evaluated and compared with each other. To investigate spatiotemporal variations, the variance of LST and NDVI values in the region and pixel scales were calculated monthly and annually and the variance maps of LST and NDVI values in pixel scale were produced. Then, the spatiotemporal variations of LST and NDVI were compared for the study area, Gomishan city and the Gomishan wetland. High values of variance for one pixel, indicated instability in the surface characteristics of the pixel during the study period. The values of this parameter are zero and positive. The larger the variance of the surface characteristic values at different times, the larger the temporal variation of that surface characteristic. Azero value of this index in any pixel indicated no variations of surface characteristics in that pixel over time. Additionally, the Coefficient of Variation (CV) has been used to evaluate the temporal changes of the average surface characteristics at the study area, the Gomishan wetland and city scales. 


\subsubsection{Spatiotemporal Changes of Surface Biophysical Characteristics Using Landsat Imagery}

Landsat images were used to more accurately compare spatiotemporal variations in the biophysical characteristics of Gomishan wetland and Gomishan city. Therefore, the variance of the Landsat-derived biophysical characteristics of the Gomishan wetland and Gomishan city were calculated and compared.

Extraction of Surface Biophysical Characteristics from Landsat Images

Radiometric conversions and atmospheric correction of Landsat satellite images were performed for the pre-processing. The details of Landsat images pre-processing are provided in [44-46].

Landsat reflective and thermal bands have been used to calculate surface biophysical characteristics. In this study, 9 widely used spectral indices, presented in Table 2, were used to extract surface biophysical characteristics. These indices include LST, impervious surfaces, vegetation, moisture, and salinity information.

Table 2. Surface biophysical characteristics used in this study.

\begin{tabular}{|c|c|c|c|}
\hline Parameters & Description & Equation & Reference \\
\hline $\begin{array}{l}\text { Normalized Difference } \\
\text { Vegetation Index (NDVI) }\end{array}$ & Indicates vegetation cover information. & $\mathrm{NDVI}=\frac{\rho_{\mathrm{NIR}}-\rho_{\mathrm{Red}}}{\rho_{\mathrm{NIR}}+\rho_{\mathrm{Red}}}$ & [47] \\
\hline $\begin{array}{l}\text { Normalized Difference } \\
\text { Salinity Index (NDSI) }\end{array}$ & Indicates surface salinity information. & NDSI $=\frac{\rho_{\operatorname{Red}}-\rho_{\mathrm{NIR}}}{\rho_{\operatorname{Red}}+\rho_{\mathrm{NIR}}}$ & [48] \\
\hline $\begin{array}{l}\text { Normalized Difference } \\
\text { Built-up Index (NDBI) }\end{array}$ & $\begin{array}{l}\text { Indicates impervious surface, bare and } \\
\text { built-up land information }\end{array}$ & $\mathrm{NDBI}=\frac{\rho_{\mathrm{MIR}}-\rho_{\mathrm{NIR}}}{\rho_{\mathrm{MIR}}+\rho_{\mathrm{NIR}}}$ & [49] \\
\hline $\begin{array}{l}\text { Normalized Difference } \\
\text { Water Index (NDWI) }\end{array}$ & $\begin{array}{l}\text { Indicates moisture information including soil moisture, } \\
\text { water-related complications, built-up land and plant }\end{array}$ & $\mathrm{NDWI}=\frac{\rho_{\mathrm{GREEN}}-\rho_{\mathrm{NIR}}}{\rho_{\mathrm{GREEN}}+\rho_{\mathrm{NIR}}}$ & [50] \\
\hline Albedo & $\begin{array}{l}\text { One of the important and effective factors on the energy } \\
\text { parameters balance, temperature and evaporation and } \\
\text { surface transpiration, which depends on the type and } \\
\text { absorption of solar radiation. }\end{array}$ & $\alpha=\frac{\alpha_{\text {toa }}-\alpha_{\text {path_radiance }}}{\tau_{\mathrm{b}}^{2}}$ & [51] \\
\hline Brightness & $\begin{array}{c}\text { First components of Tasseled Cap Transformation (TCT), } \\
\text { indicates information on the percentage of impermeable } \\
\text { surfaces including bare and constructed land }\end{array}$ & & \multirow[t]{2}{*}[52,53]{} \\
\hline Wetness & $\begin{array}{c}\text { Third components of Tasseled Cap Transformation (TCT), } \\
\text { indicates the characteristics of water, soil, plant and } \\
\text { constructed lands related effects }\end{array}$ & & \\
\hline $\begin{array}{c}\text { Land Surface } \\
\text { Temperature (LST) }\end{array}$ & $\begin{array}{l}\text { LST is one of the important parameters for controlling and } \\
\text { evaluating the biological, chemical and physical processes } \\
\text { of the Earth's surface and is an important factor for } \\
\text { studying the Earth's ecological conditions and land } \\
\text { resource management activities. }\end{array}$ & $=\gamma\left(\frac{1}{\operatorname{LST}}\left(\psi_{1} \mathrm{~L}_{\mathrm{sen}}+\psi_{2}\right)+\psi_{3}\right)$ & [54-56] \\
\hline Salinity Index 1 (SI1) & $\begin{array}{l}\text { Indicates the salt affected lands with } \\
\text { sparse vegetation cover }\end{array}$ & SI $1=\frac{\rho_{\text {NIR }} \times \rho_{\text {Red }}}{\rho_{\text {Green }}}$ & [48] \\
\hline
\end{tabular}

\subsubsection{Land Cover Classification}

Land cover classes in the study area were determined based on information obtained from field surveys and visual interpretation of Landsat RGB (red, green and blue) images. These classes include urban, green space, water, and bare soil lands. In this study, the maximum likelihood method was used for image classification. In this method, after evaluating the probabilities in each class, the pixels are assigned to the class with the highest probability [57].

Training and test datasets are needed to supervise the classification of satellite imagery and evaluate land cover classification results. In this study, training and test datasets were collected through visual interpretation of false color composite images, field survey-derived information, and Google Earth images. For each land cover class, more than 300 training samples were selected for classification, and 200 test samples were selected for evaluation. To assess the accuracy of the land cover maps prepared from the classification, Kappa coefficient and overall accuracy criteria were used. After preparing the land cover maps, the area of each class and the amount of its change during the period of 
1987 to 2017 were calculated and evaluated. Finally, the CV was used to compare the temporal changes of the Gomishan wetland and city.

\subsubsection{Modeling the Surface Ecological Conditions}

In this study, RSEI was used to model the surface ecological conditions $[15,26]$. To model the surface ecological conditions based on this index, the main information of the surface characteristics, including surface heat, greenness, dryness, and wetness, were combined with each other (Equation (1)). To assessing the surface ecological conditions based on RSEI, first, the values of the used indices including NDVI, wetness, LST and brightness were standardized between 0 and 1 to reduce the effect of climatic and meteorological conditions and co-scaling of information obtained from different indicators and sensors on the results of the RSEI.

$$
\text { RSEI }=\text { PCA(NDVI, Wetness, LST, Brightness })
$$

PCA was utilized here for identifying the relative importance of NDVI, wetness, LST and brightness variables. The eigenvalue of the first component of PCA (PC1) integrates most characteristics of all variables, and therefore a surface ecological conditions map was built with PC1 in this study $[5,15,26,34]$. The value of the RSEI index is standardized between 0 and 1 . RSEI values of 1 and 0 indicate the worst and best surface ecological conditions, respectively. Finally, the RSEI was classified according to 5 classes of surface ecological conditions, which were very good $(0-0.2)$, good $(0.2-0.4)$, acceptable (0.4-0.6), bad (0.6-0.8), and very bad $(0.8-1)[14,15]$. After preparing classified RSEI maps, the mean of RSEI and the area of each surface ecological condition class during the period of 1987 to 2017 were calculated. Variance was used to evaluate the temporal changes of surface ecological conditions at the pixel scale and CV was used to evaluate and compare the temporal changes of the average RSEI and the area of surface ecological conditions classes at the scale of Gomishan wetland and city. High values of variance and $\mathrm{CV}$ indicate high temporal changes in surface ecological conditions.

\section{Results}

\subsection{NDVI and LST Spatiotemporal Variations of the Study Area Using MODIS Products}

The LST means of the study area were 12.0, 13.9, 18.6, 24.7, 31.8, 35.5, 36.5, 37.5, 34.1, 28.2, 19.3, and $12.8{ }^{\circ} \mathrm{C}$ in the months of January, February, March, April, May, June, July, August, September, October, November, and December, respectively (Figure 3). The temporal variations the LST mean for the study area vary in different months. On a monthly scale, the highest and lowest standard deviation (SD) of LST means for the study area were April $\left(2.5^{\circ} \mathrm{C}\right)$ and February $\left(1.3^{\circ} \mathrm{C}\right)$, respectively.

The LST means for the study area in winter, spring, summer, and autumn were 14.9, 30.7, 36.1, and $20.2{ }^{\circ} \mathrm{C}$, respectively. The highest and lowest coefficient of variation (CV) of the LST were for winter (0.08) and summer (0.04), respectively. Additionally, the LST mean for the study area varies for different years. The highest and lowest LST means were for 2010 (27.1) and 2002 (23.5), respectively.

The NDVI means for the study area were $0.19,0.23,0.29,0.29,0.23,0.16,0.15,0.15,0.16,0.16,0.15$, and 0.17 in different months, respectively (Figure 4). Additionally, the monthly mean of NDVI for the region varies for different years. The highest and lowest NDVI means were for $2010(0.24)$ and 2001 (0.14), respectively. As with LST, the CVs of the monthly NDVI mean in April (0.06), March (0.06), February (0.05) and May (0.05) were higher than in other months, while the lowest CV of the monthly NDVI mean was in September (0.01). The highest and lowest CV of NDVI were for spring (0.19) and summer (0.09), respectively. 


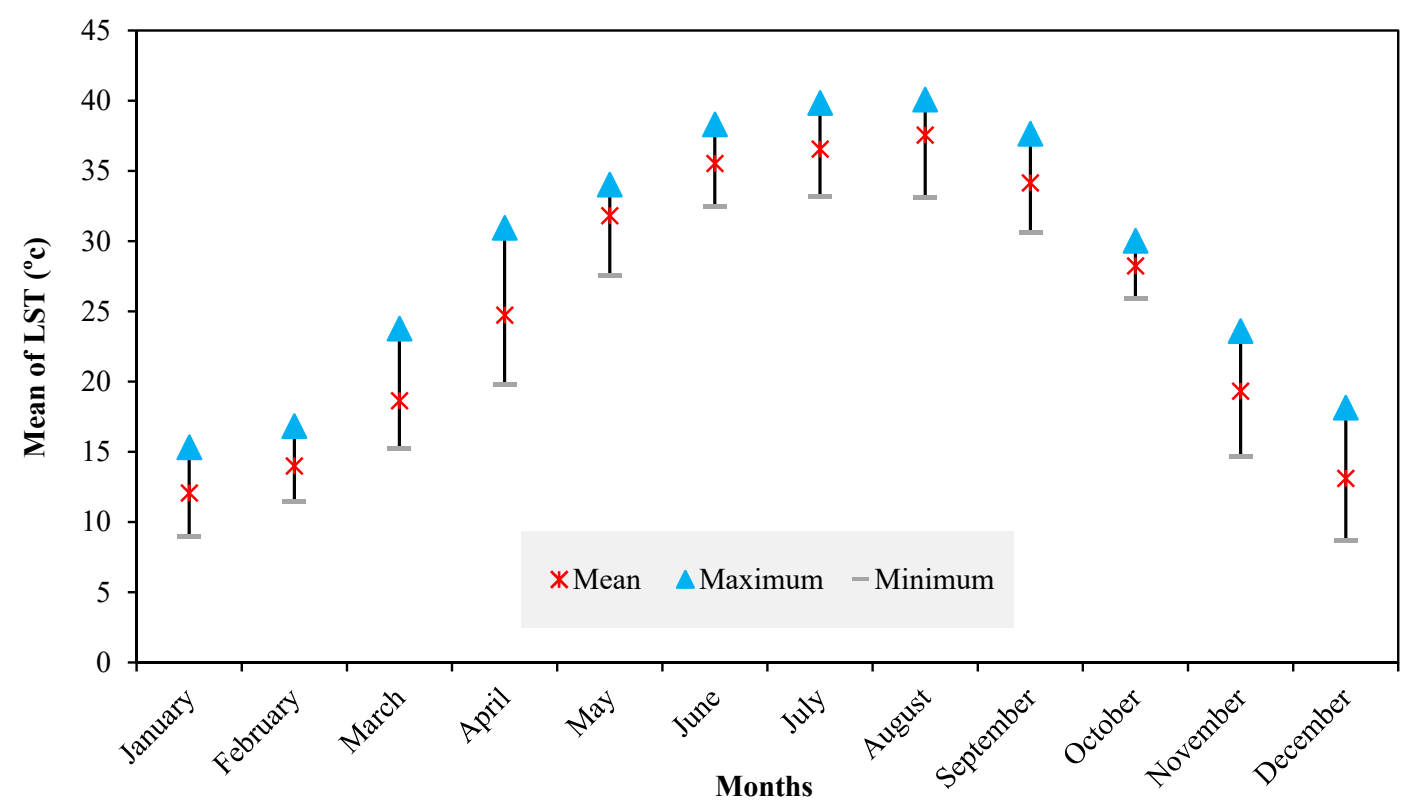

Figure 3. The LST mean for the study area obtained from MODIS products (MOD11C3) with $5000 \mathrm{~m}$ spatial resolution.

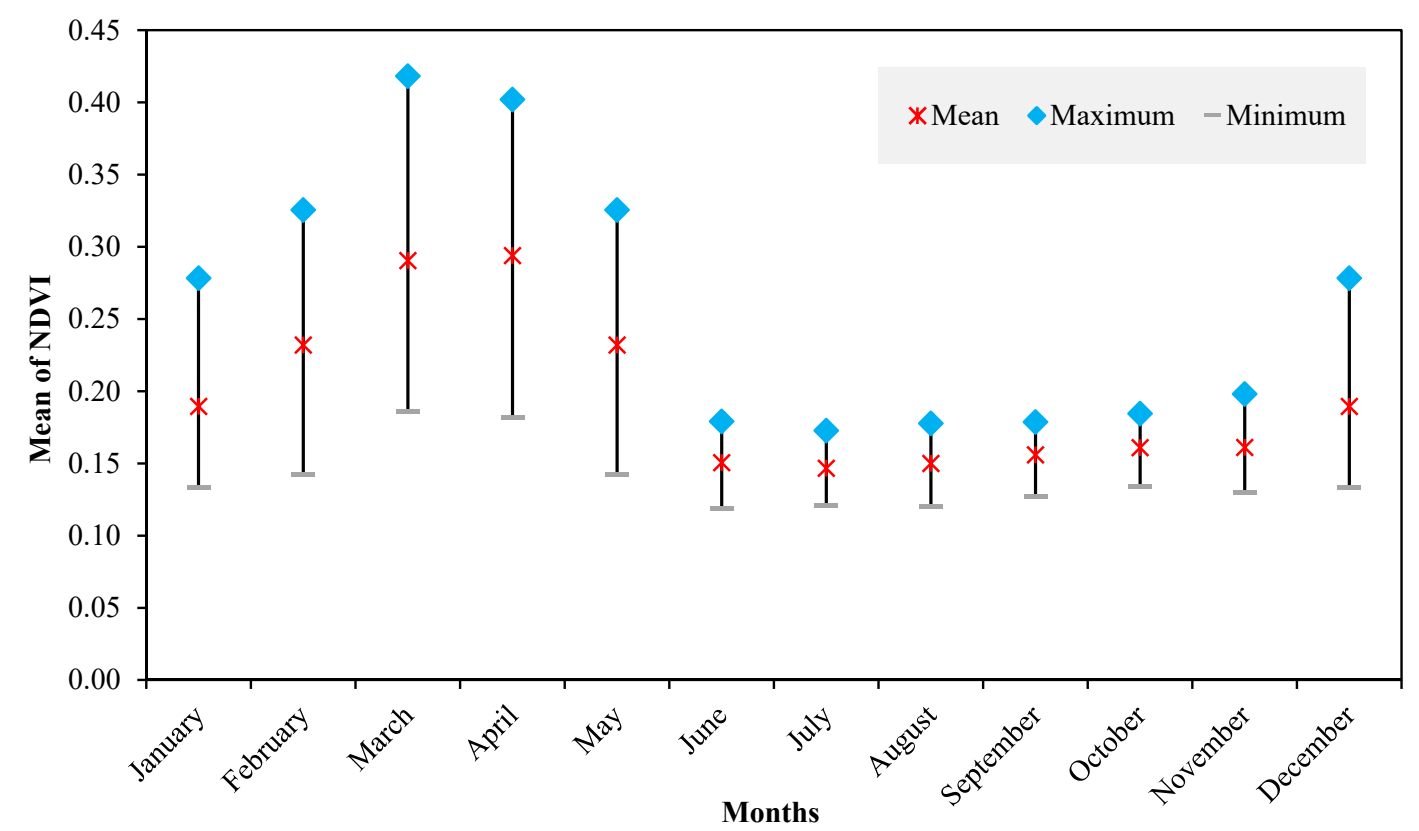

Figure 4. The NDVI mean for the study area obtained from MODIS products (MOD13C3) with $5000 \mathrm{~m}$ spatial resolution.

The LST means for Gomishan city and the Gomishan wetland in different months in the period of 2000-2017 is shown in Figure 5. The trend of LST mean temporal variations in these two parts of the study area between 2000 and 2017 was similar. The difference between the LST means of the wetland and the city of Gomishan were high in some dates. However, in a significant number of months in different years, the LST means for Gomishan city and the Gomishan wetland were almost equal. 

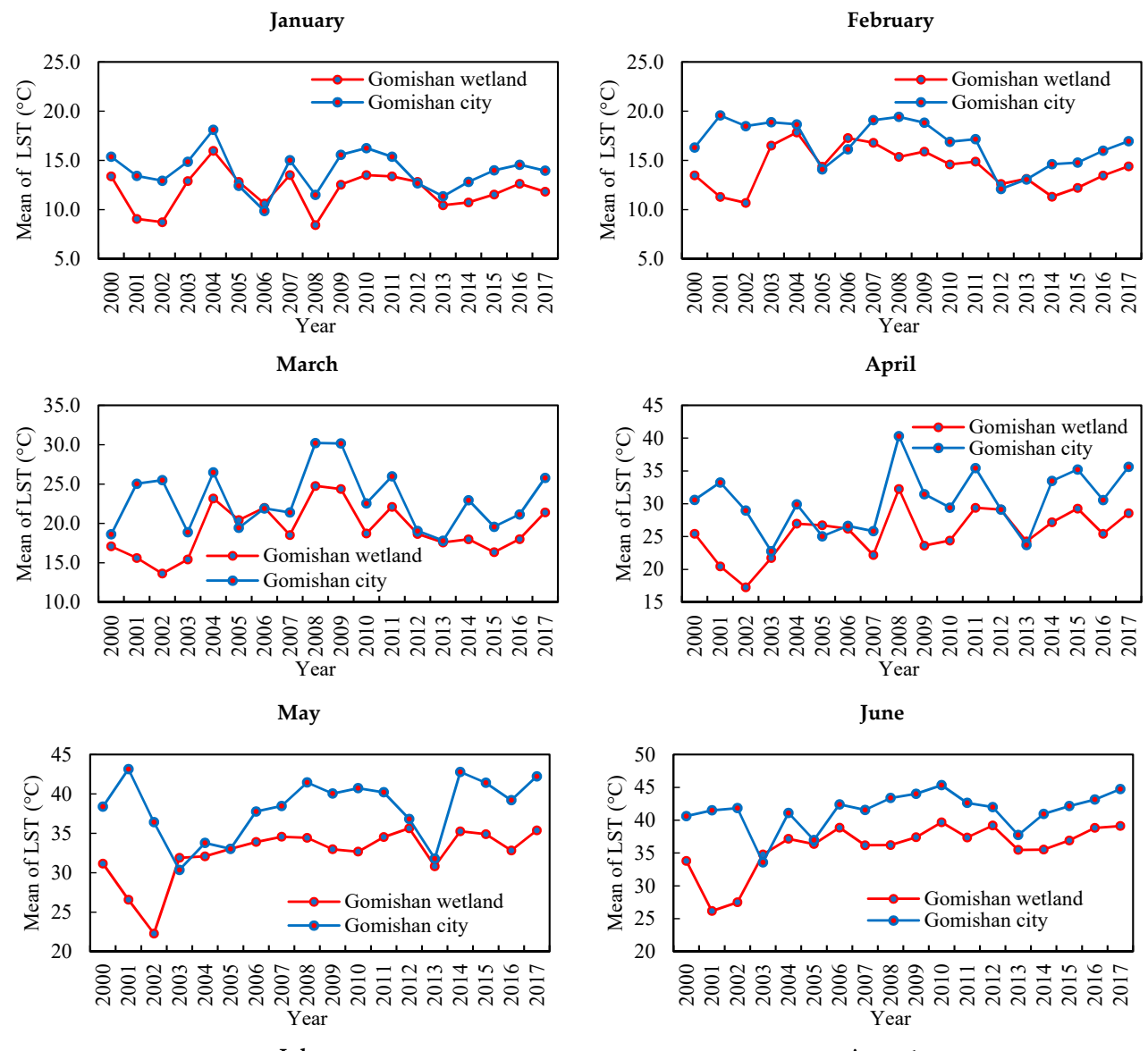

July

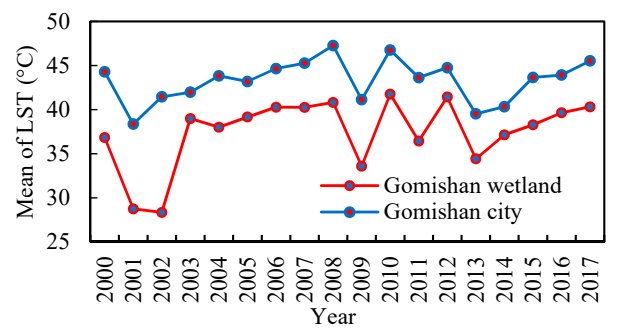

September
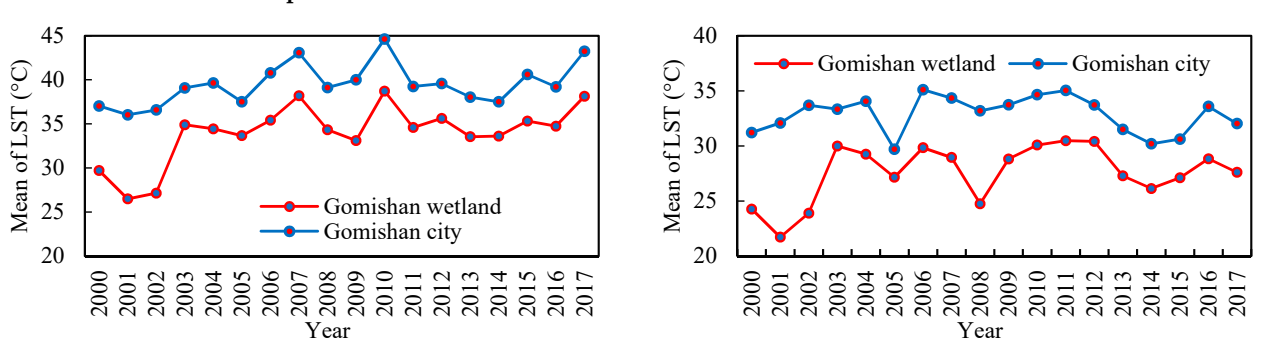

November

\section{December}
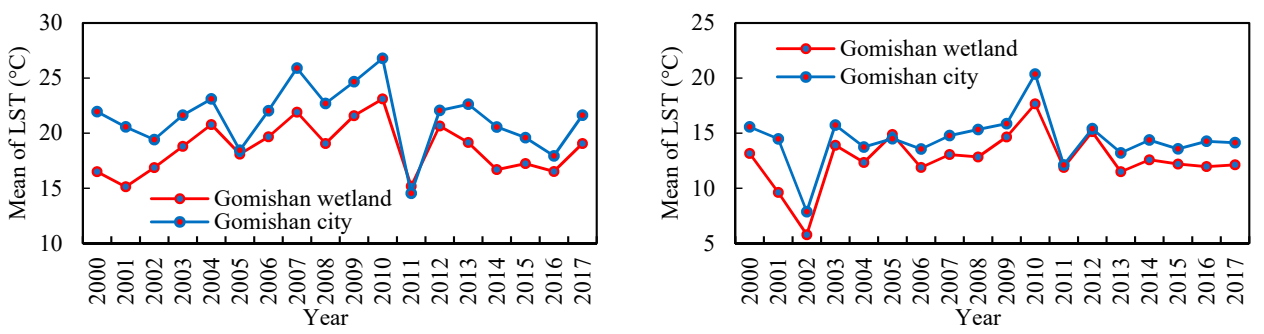

Figure 5. The LST mean for Gomishan city and wetland by different months in the period of 2000-2017. 
The LST variance values of each pixel for each month are shown in Figure 6. Areas with high (red) and low (green) variance values have high and low temporal variations of LST, respectively. The spatial distribution of LST variance varies in different months and areas. The mean of LST variance values of the study area were $3(1), 4(2), 8$ (6), $11.6(8.1), 7.1(6.0), 5.5(5.5), 5.9(4.9), 7.5(5.7), 6.1(4.1)$, 4.3 (3.0), 6.9 (4.1), and $4.6(2.5)^{\circ} \mathrm{C}$ January through December, respectively.
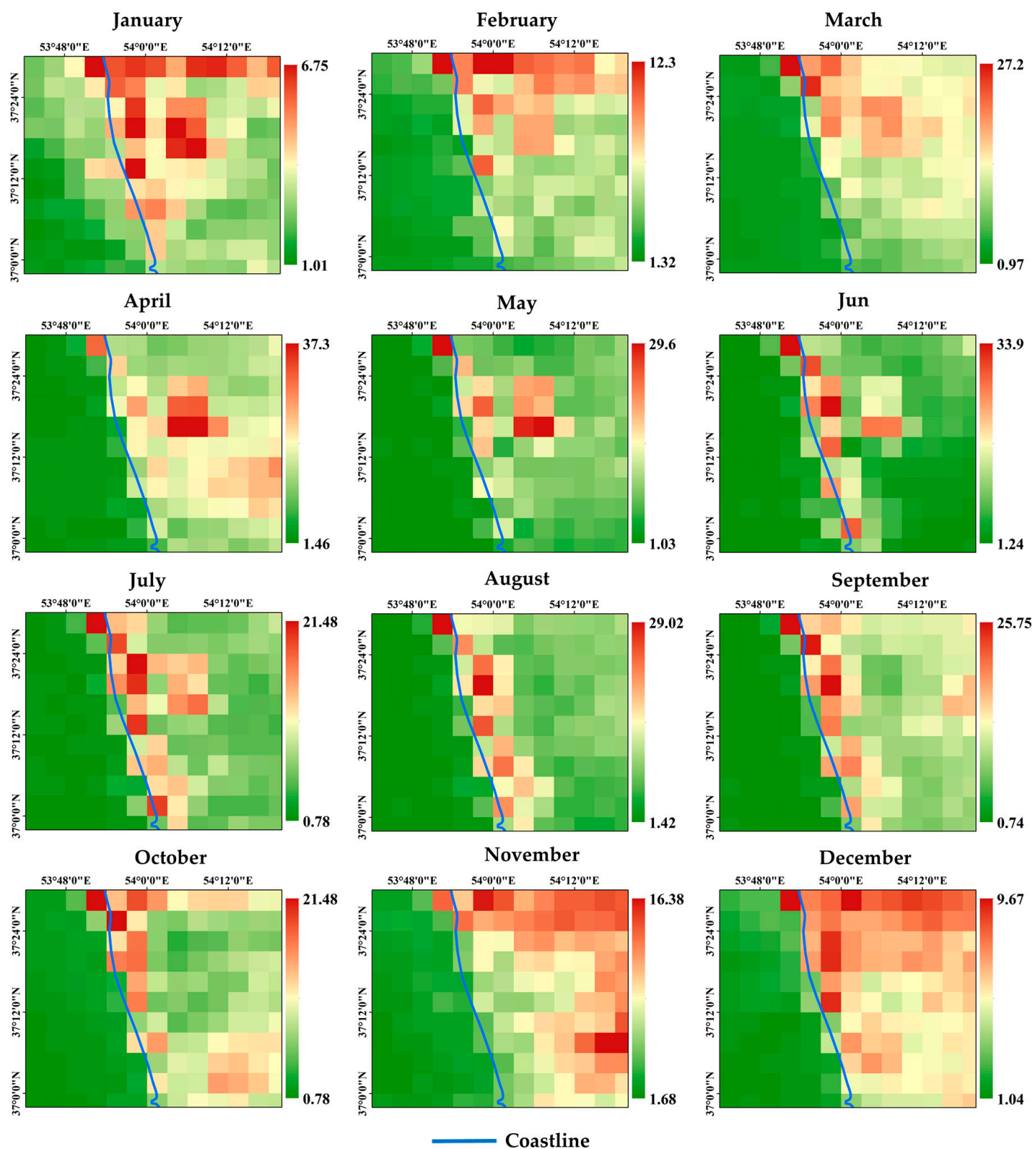

Figure 6. Variance maps of LST for different months in the period of 2000-2017.

The mean LST variance values for winter, spring, summer, and autumn were 5.5, 8.1, 6.5, and 5. ${ }^{\circ} \mathrm{C}$, respectively. The LST of the Gomishan wetland changed more in June, July, August, and September than in other months, which indicates high temporal variations in the wetland's water level during these months. In general, the temporal variations of LST in the northern half of the region were greater than in the southern half. The temporal variations of LST in the eastern part of the region, which includes the Caspian Sea, were lower than in other areas.

The NDVI variance values for the study area were calculated separately for different months and are shown in Figure 7 in pixel scale. The results show that the temporal variation of NDVI for the 
margins of the southeastern areas of the region with agricultural lands and the Caspian Sea were high in January, March, February, April, and May. However, for June, July, August, September, October, November, and December, high levels of NDVI variance were limited to the Caspian Sea margins. The highest and lowest NDVI variance values were in March (0.023) and August (0.008), respectively. Additionally, the spatial distribution of NDVI variance varies in different months and locations.
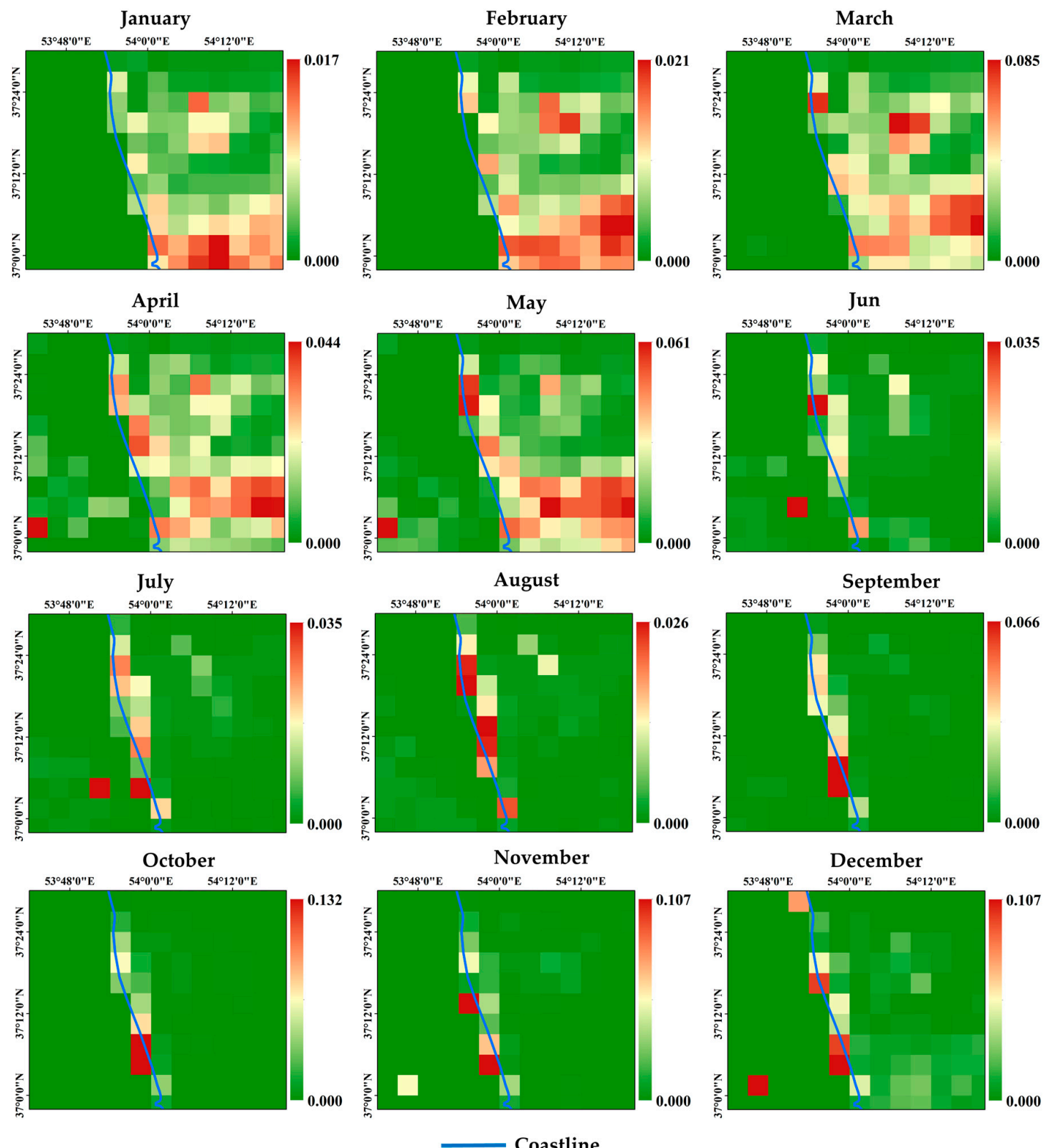

Figure 7. Variance maps of NDVI for different months in the period of 2000-2017.

The LST and NDVI variance maps of each pixel were calculated annually, and the results are shown in Figure 8. The mean (SD) values of the LST and NDVI variance of the study area were 6.54 (4.04) ${ }^{\circ} \mathrm{C}$ and 0.009 (0.006), respectively. The correlation coefficient ( $r$ ) between the LST and NDVI variance values of the study area is 0.78 , which indicates the spatial consistency of LST and NDVI temporal variations in the study area. The mean of the LST (NDVI) variance for Gomishan city and the Gomishan wetland were $2.1(12.1){ }^{\circ} \mathrm{C}$ and 0.005 (0.013), respectively. Most of the temporal variations in LST and NDVI for the region were related to the Gomishan wetland that is bordered by the Caspian Sea. 
The results showed that during the period of 2000 to 2017, the temporal variations in the Gomishan wetland's LST and NDVI were greater than those in Gomishan city.
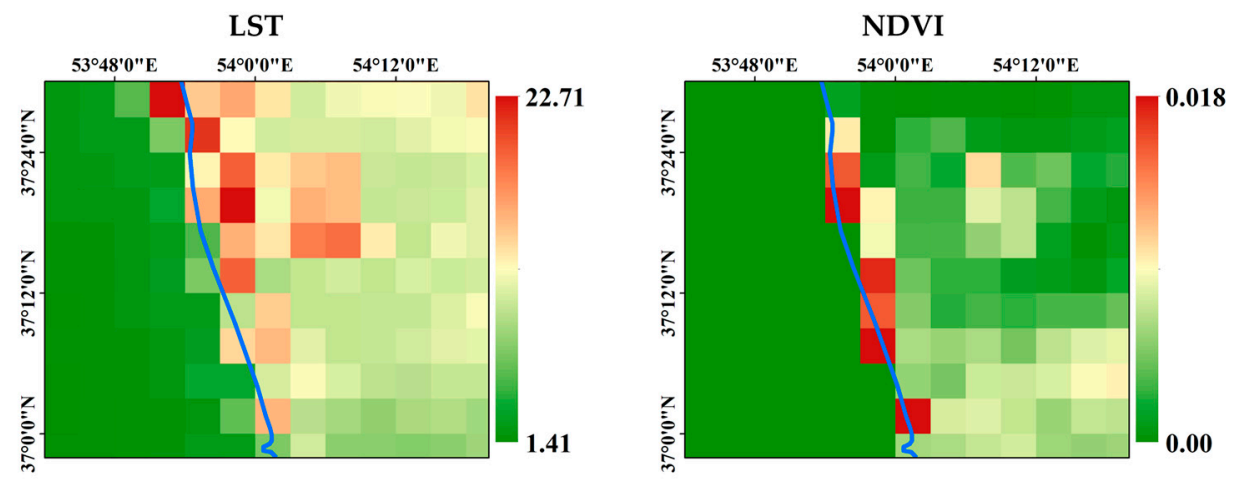

Coastline

Figure 8. Annual variance maps of LST and NDVI.

\subsection{Spatiotemporal Variations in Biophysical Characteristics Using Landsat Images}

The mean of surface biophysical characteristics for the study area (Gomishan city and the Gomishan wetland) was calculated using Landsat imagery (Figure 9). The mean of surface biophysical characteristics was different in various land cover classes. Additionally, the difference between the means of surface biophysical characteristics for different locations in the study area (the Gomishan wetland and Gomishan city) was high. Due to water cover, the average amount of LST, NDVI, NDBI, brightness, albedo and SI1 in the Gomishan wetland is less than other areas.

LST

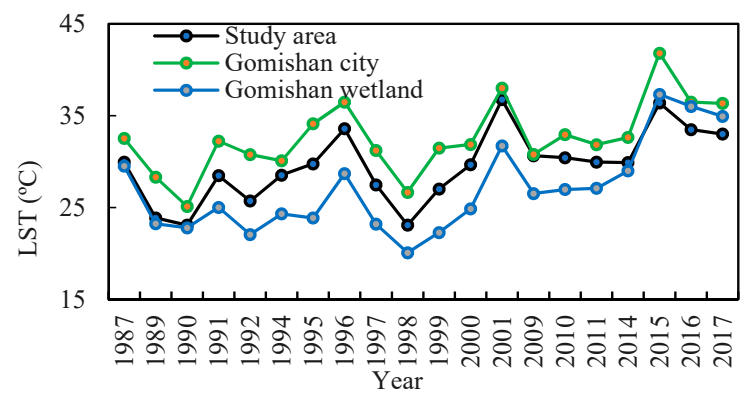

NDWI

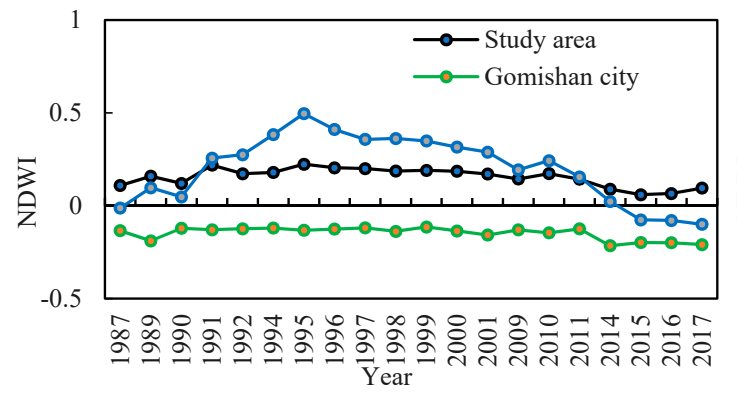

NDVI

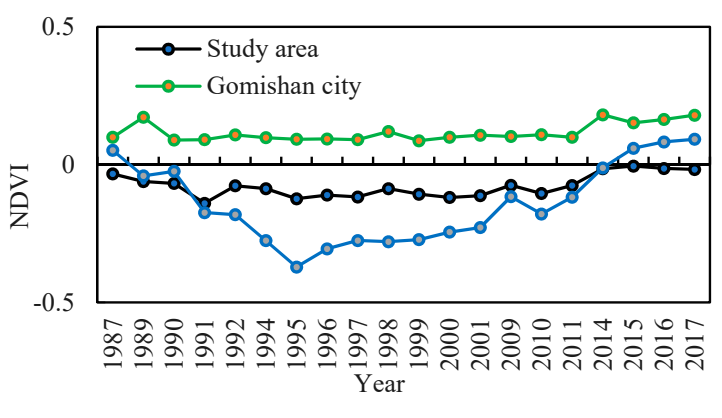

NDBI

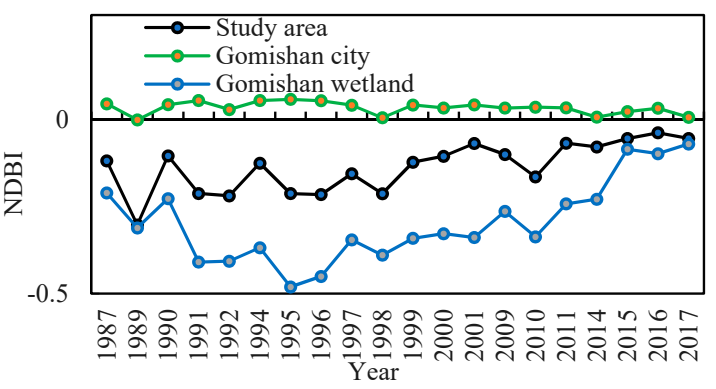

Figure 9. Cont. 
Brightness

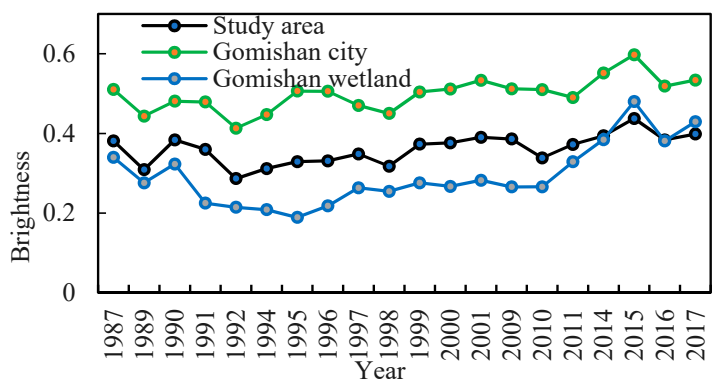

Albedo

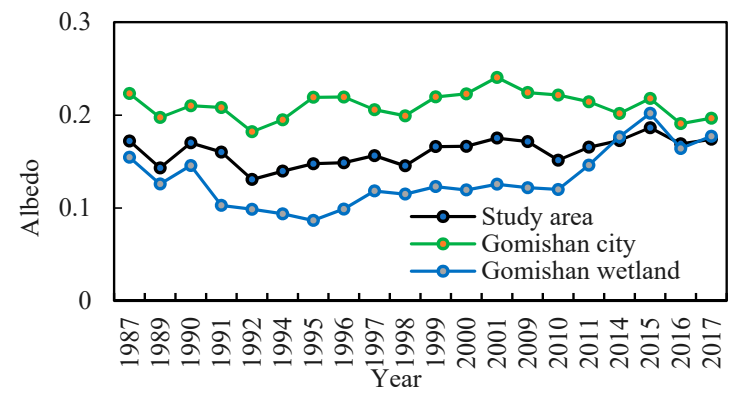

Wetness

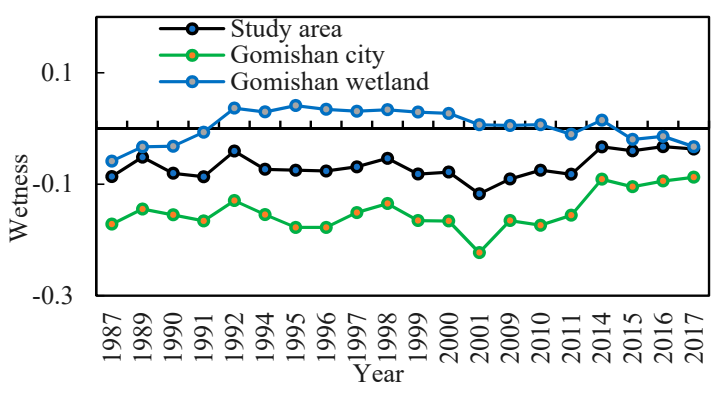

NDSI

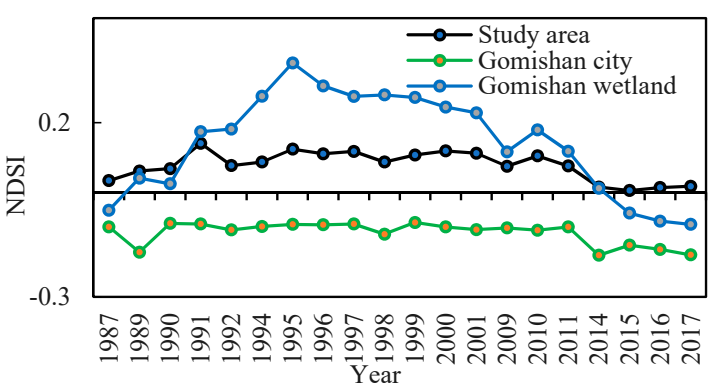

SI1

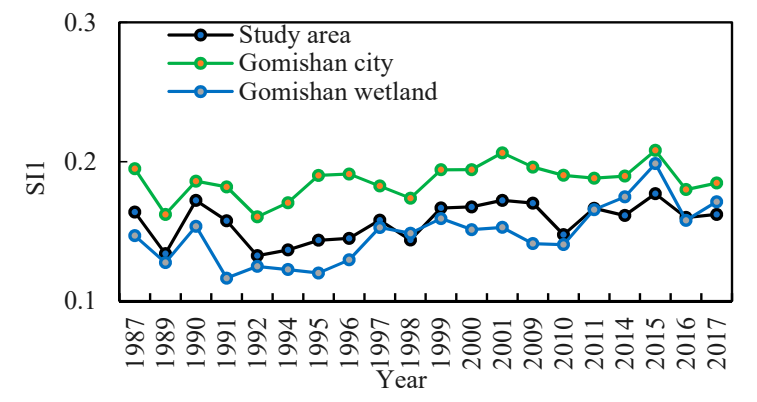

Figure 9. Mean of surface biophysical characteristics for the Gomishan wetland, Gomishan city, and study area using Landsat imagery.

The SD of the mean values of LST, NDVI, NDWI, NDBI, brightness, albedo, wetness, NDSI, and SI1 for the study area (Gomishan city and the Gomishan wetland) were $3.7(3.7,4.7){ }^{\circ} \mathrm{C}, 0.04(0.03$, $0.14), 0.04$ (0.03, 0.17), 0.07 (0.01, 0.11$), 0.03$ (0.04, 0.07), 0.01 (0.01, 0.03), $0.02(0.02,0.03), 0.04$ (0.03, $0.14)$, and $0.01(0.01,0.02)$, respectively. Gomishan city and the Gomishan wetland have the lowest and highest temporal variations in biophysical characteristics, respectively. Additionally, the highest (lowest) CV of biophysical characteristics of the Gomishan wetland, Gomishan city and study area is related to the wetness (SI1), NDBI (albedo), and NDVI (SI1), respectively. The LST temporal variation trend in the region is generally increasing.

Temporal variations of the biophysical characteristics were calculated on a pixel scale, and the results are presented in Figure 10. The biophysical characteristics temporal variation was heterogeneous. Most of the biophysical characteristics temporal variations in the study area are in the Gomishan wetland.

The mean surface biophysical characteristics variance values for the Gomishan wetland, Gomishan city, and the study area were calculated (Table 3). The temporal variation in surface biophysical characteristics was higher in the Gomishan wetland and lower in Gomishan city. Additionally, the highest and lowest temporal variations in surface biophysical characteristics were related to NDVI and albedo, respectively. 

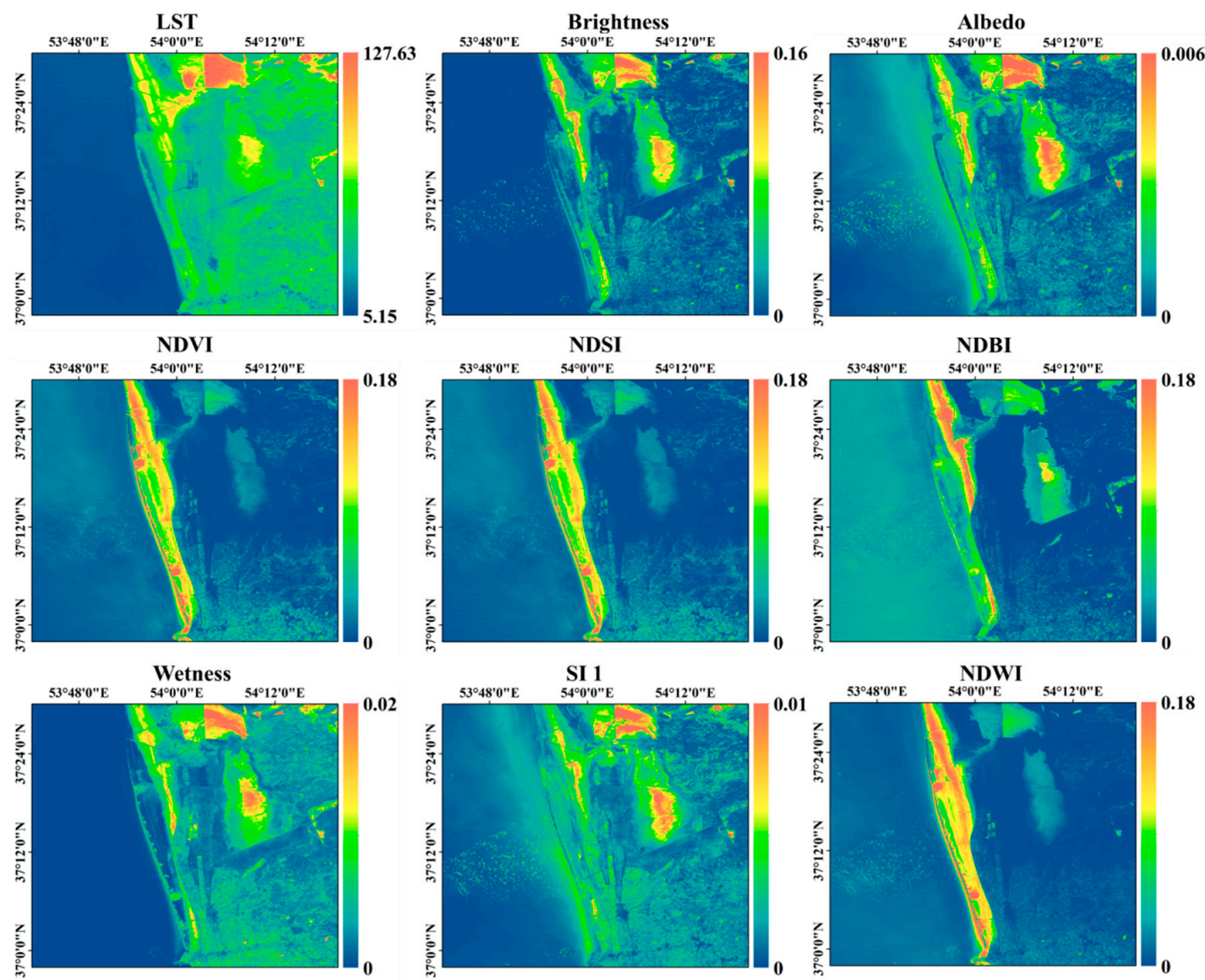

Figure 10. Variance of surface biophysical characteristics values between 1987 and 2017 at the pixel scale.

Table 3. The mean surface biophysical characteristics variance values for the Gomishan wetland, Gomishan city, and study area between 1987 and 2017.

\begin{tabular}{cccccccccc}
\hline Parameter & LST $\left({ }^{\circ} \mathbf{C}\right)$ & NDVI & NDBI & NDWI & Brightness & Wetness & Albedo & NDSI & SI 1 \\
\hline $\begin{array}{c}\text { Study } \\
\text { area }\end{array}$ & 21.5 & 0.009 & 0.018 & 0.011 & 0.004 & 0.002 & 0.001 & 0.009 & 0.001 \\
$\begin{array}{c}\text { City } \\
\text { Talab }\end{array}$ & 15.3 & 0.002 & 0.001 & 0.002 & 0.003 & 0.001 & 0.001 & 0.002 & 0.001 \\
\hline
\end{tabular}

\subsection{Land Cover Maps}

Mean overall classification accuracy (kappa coefficient) of urban, bare land, green space and water classes on different dates was 90 (0.89), 92 (0.90), 93 (0.92) and 95 (0/93), respectively. The highest and lowest classification accuracy was for water and urban classes, respectively. The evaluation results showed that the accuracy of land cover maps obtained from the satellite images classification was acceptable [55,58]. Land cover maps for the study area are shown in Figure 11. The spatiotemporal variations of land covers in the study area were very high. In recent years, the water area in the Gomishan wetland has changed significantly, which is a function of the inward and outward movements of the Caspian Sea. Moreover, the amount of vegetation in the northern part of the study area has decreased significantly, which has led to an increase in the amount of bare lands in these areas. However, in the south of the study area, some of the bare lands have turned into green and agricultural lands. 


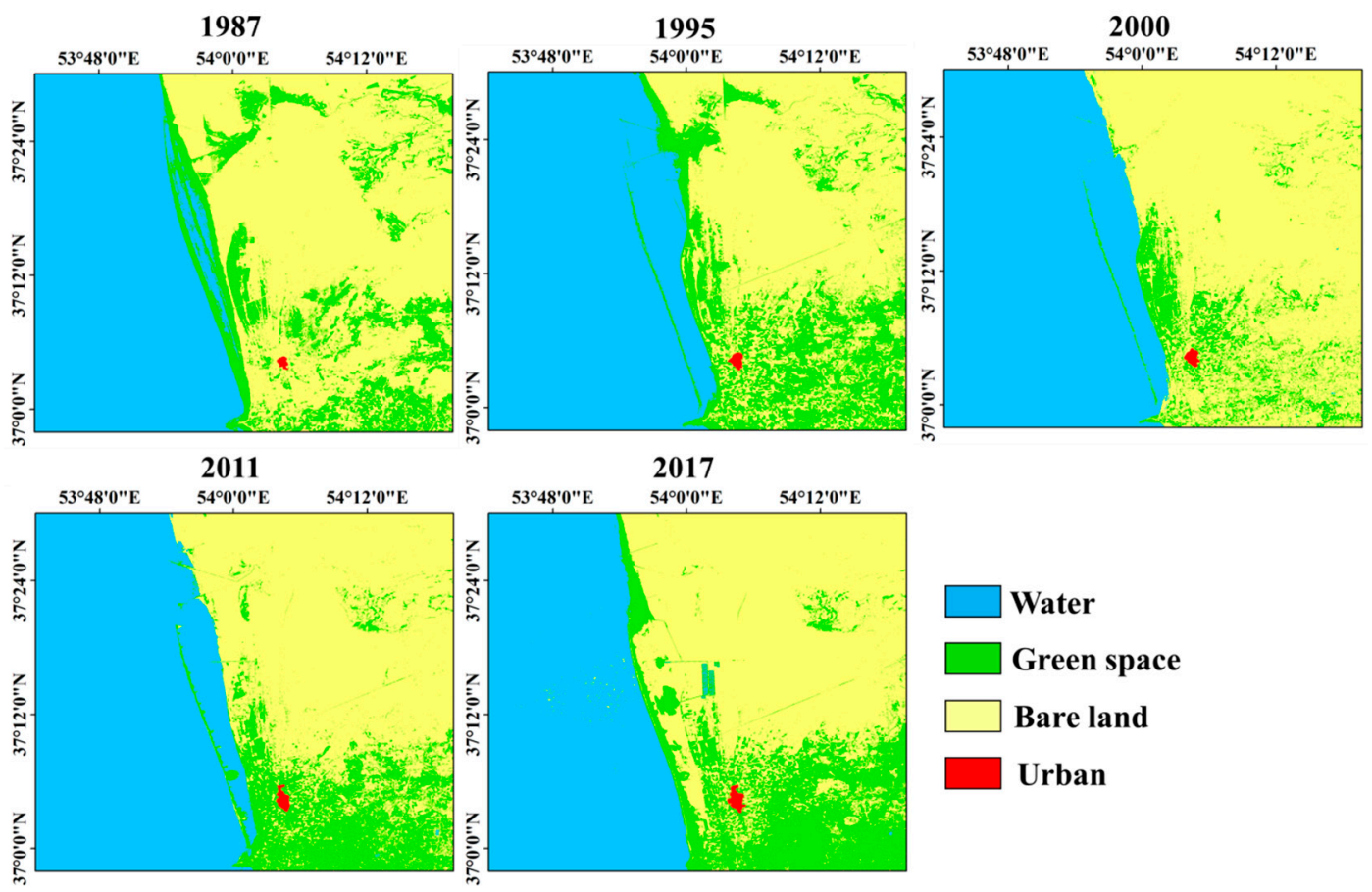

Figure 11. Land cover maps of the study area.

The areas of different land cover classes in the study period are shown in Table 4 . The area of Gomishan city has increased from $2.15 \mathrm{Km}^{2}$ in 1987 to $6.48 \mathrm{Km}^{2}$ in 2017 . The highest and lowest green space areas were found in $1992(715)$ and $1994\left(323 \mathrm{Km}^{2}\right)$. The CV of the area of urban, bare soil, green space, and water lands were $0.34,0.11,0.36$, and 0.06 , respectively. The results show that the spatial and temporal changes in the green space lands were greater than those in other land covers in the study area.

Table 4. Land cover area of the study area for the period of 1987 to $2017\left(\mathrm{Km}^{2}\right)$.

\begin{tabular}{ccccc}
\hline Year & Urban & Green Space & Bare Soil & Water \\
\hline 1987 & 2.15 & 489.79 & 1606.94 & 1419.52 \\
1989 & 2.29 & 552.51 & 1438.60 & 1525.00 \\
1990 & 2.36 & 643.27 & 1369.90 & 1502.88 \\
1991 & 2.48 & 700.46 & 1283.61 & 1531.85 \\
1992 & 2.61 & 715.86 & 1031.44 & 1768.49 \\
1994 & 2.95 & 323.34 & 1584.69 & 1607.41 \\
1995 & 3.1 & 556.00 & 1321.59 & 1637.71 \\
1996 & 3.35 & 210.66 & 1691.10 & 1613.29 \\
1997 & 3.51 & 540.01 & 1368.59 & 1606.29 \\
1998 & 3.7 & 468.05 & 1432.32 & 1614.33 \\
1999 & 3.9 & 349.04 & 1554.36 & 1611.09 \\
2000 & 4.05 & 240.14 & 1664.88 & 1609.33 \\
2001 & 4.18 & 251.89 & 1672.63 & 1589.70 \\
2009 & 4.8 & 250.61 & 1709.68 & 1553.31 \\
2010 & 4.9 & 557.62 & 1385.16 & 1570.72 \\
2011 & 5.05 & 454.50 & 1500.03 & 1558.82 \\
2014 & 5.9 & 486.44 & 1518.17 & 1507.90 \\
2015 & 6.16 & 495.93 & 1619.31 & 1397.00 \\
2016 & 6.29 & 598.74 & 1547.50 & 1365.86 \\
2017 & 6.48 & 507.13 & 1614.41 & 1390.38 \\
\hline
\end{tabular}


The temporal variation trend of water land area in the Gomishan wetland is shown in Figure 12. The temporal variations in the water land area of this wetland have changed during the study period. From 1987 to 1995, the changes in the water land area in the Gomishan wetland increased, but from 1995 to 2017, they decreased. The highest and lowest water land area in the Gomishan wetland were in $1995(22.04)$ and $2016\left(237.17 \mathrm{~km}^{2}\right)$, respectively. The CV of the water land area in the Gomishan wetland and Gomishan city area were 0.45 and 0.34 , respectively, which indicates more changes in the water land area in the Gomishan wetland than in Gomishan city.

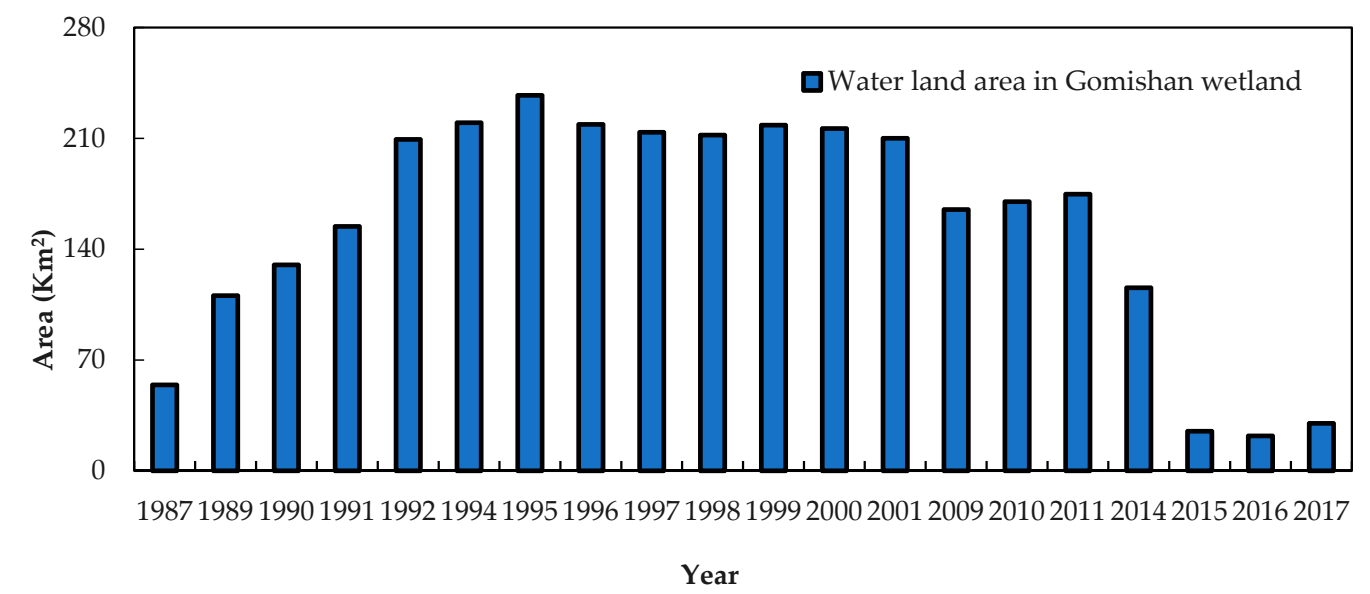

Figure 12. The water land area in the Gomishan wetland between 1987 to 2017.

\subsection{Spatiotemporal Variations of the Surface Ecological Conditions}

The RSEI means for the study area, Gomishan city and the Gomishan wetland, were 0.43, 0.65, and 0.29 , respectively (Figure 13). The surface ecological conditions of Gomishan city were worse than the surface ecological conditions of the study area and the Gomishan wetland. The CV of RSEI means for the study area, Gomishan city, and the Gomishan wetland were $0.10,0.88$, and 0.51 , respectively. The surface ecological conditions of these lands have changed during the study period. Temporal variations in the surface ecological conditions of the Gomishan wetland were greater than in the study area and Gomishan city. The lowest and highest RSEI means were in 1995 (0.11) and 2015 (0.63), respectively.

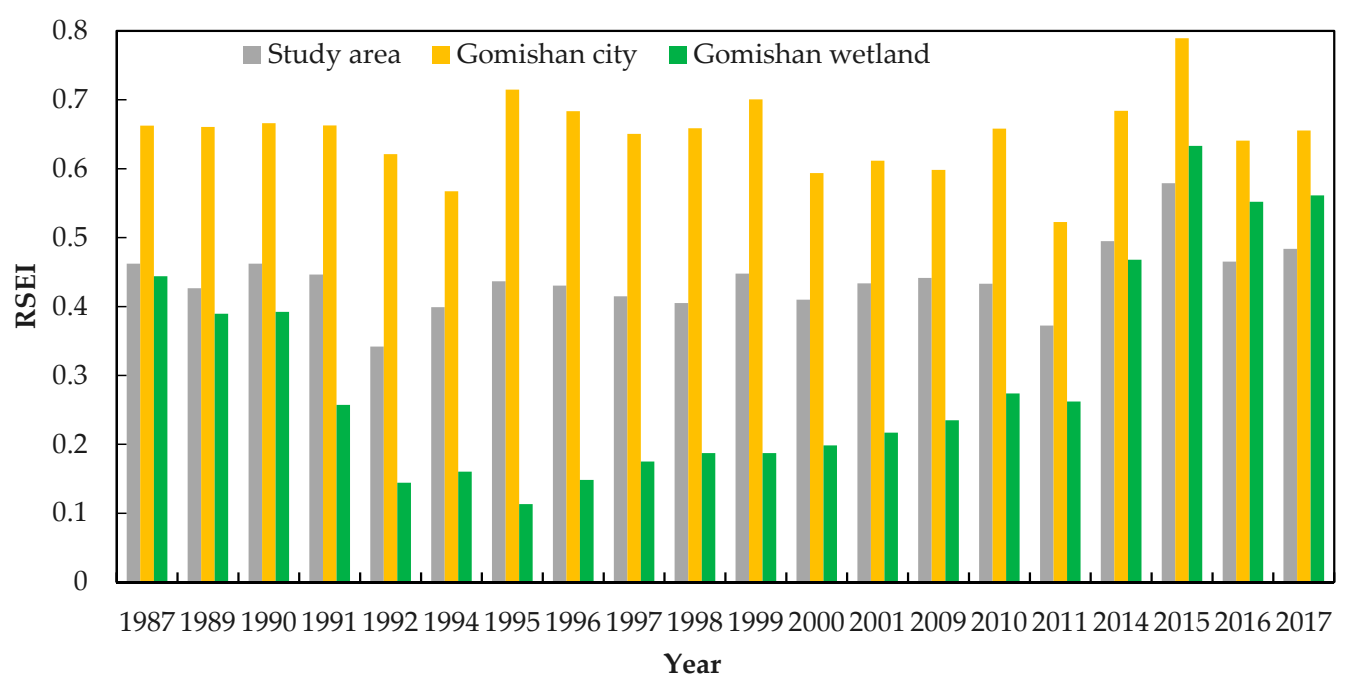

Figure 13. The RSEI mean for the study area, Gomishan wetland, and the Gomishan city. 
The $r$ between the water land areas in the Gomishan wetland and the RSEI means for the Gomishan wetland and the study area were -0.96 and -0.69 , respectively (Figure 14). With the advancement of the Caspian Sea and the increase in the water land area in the Gomishan wetland, the quality of surface ecological conditions in this region has improved.
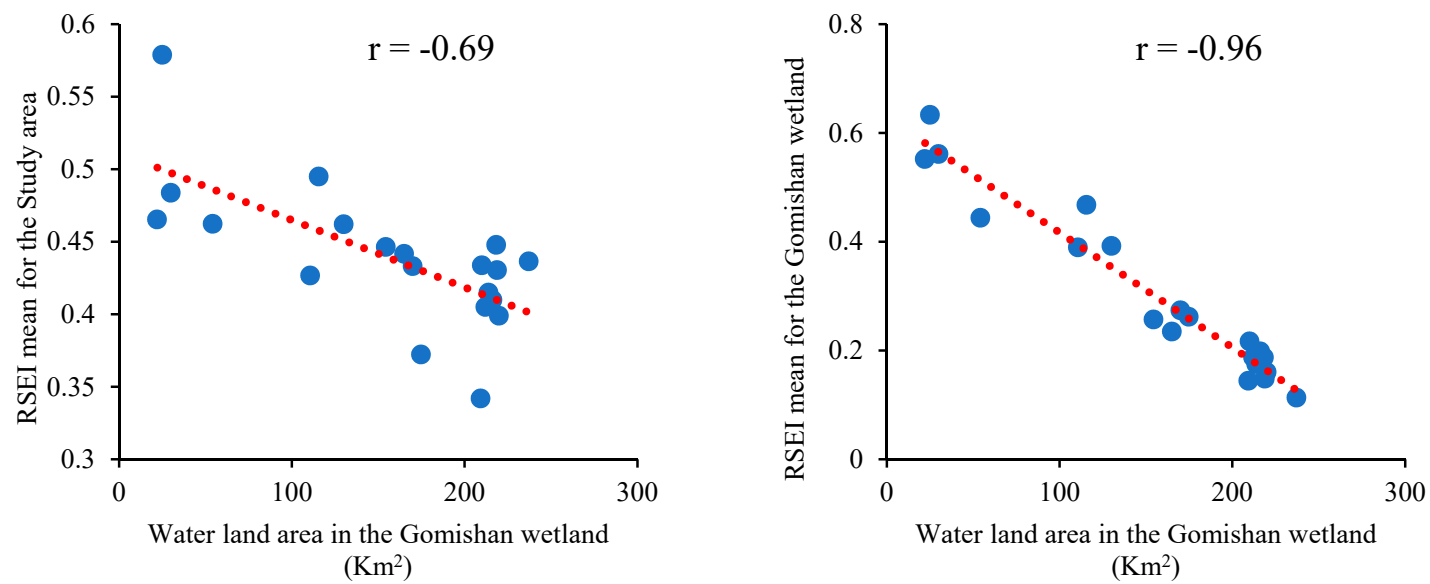

Figure 14. The $r$ between the water land areas in the Gomishan wetland and the RSEI means for the Gomishan wetland and the study area between 1987 to 2017.

A visual survey of classified RSEI maps shows that the spatial distribution of surface ecological conditions varies at different dates (Figure 15). The areas covered with bare soil have poor surface ecological conditions, and the areas covered with water have excellent surface ecological conditions. With the retreat of water from the Gomishan wetland between 1987 and 2017, the surface ecological conditions of this part of the region have changed from excellent and very good to good.
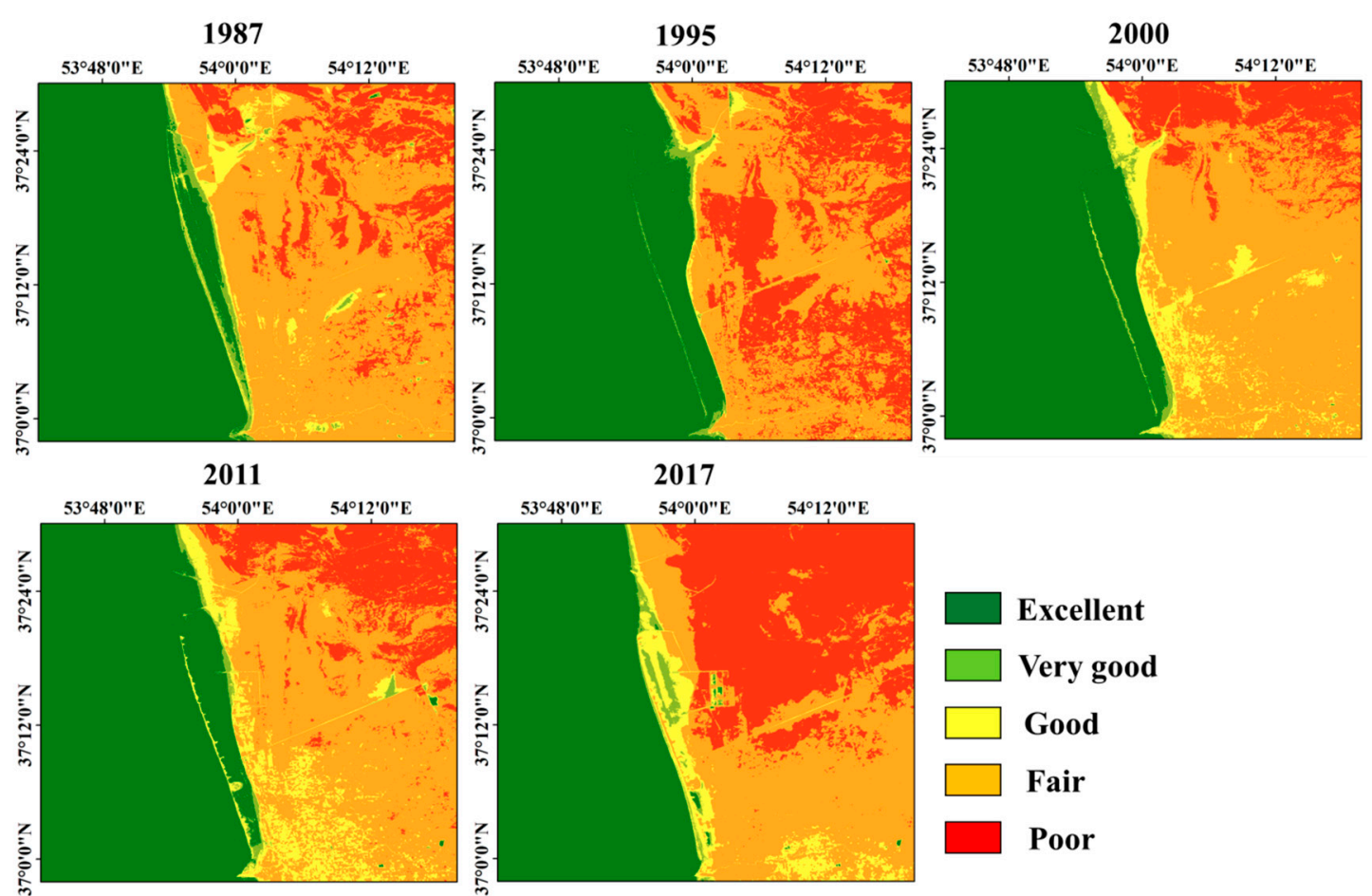

Figure 15. Classified RSEI maps of the study area. 
The areas of surface ecological condition classes were calculated, and the results are shown in Figure 16. Variations in the temporal and spatial dimensions of the study area's ecological conditions include both different class areas and different class types. Over the years, the surface ecological condition has worsened and most of the study area is now in the poor class. The CVs of the excellent, very good, good, fair, and poor surface ecological conditions' classes' areas were $0.09,0.87,0.77,0.23$, and 0.63 , respectively. The maximum temporal variations among the classes of the surface ecological conditions were related to the Gomishan wetland.

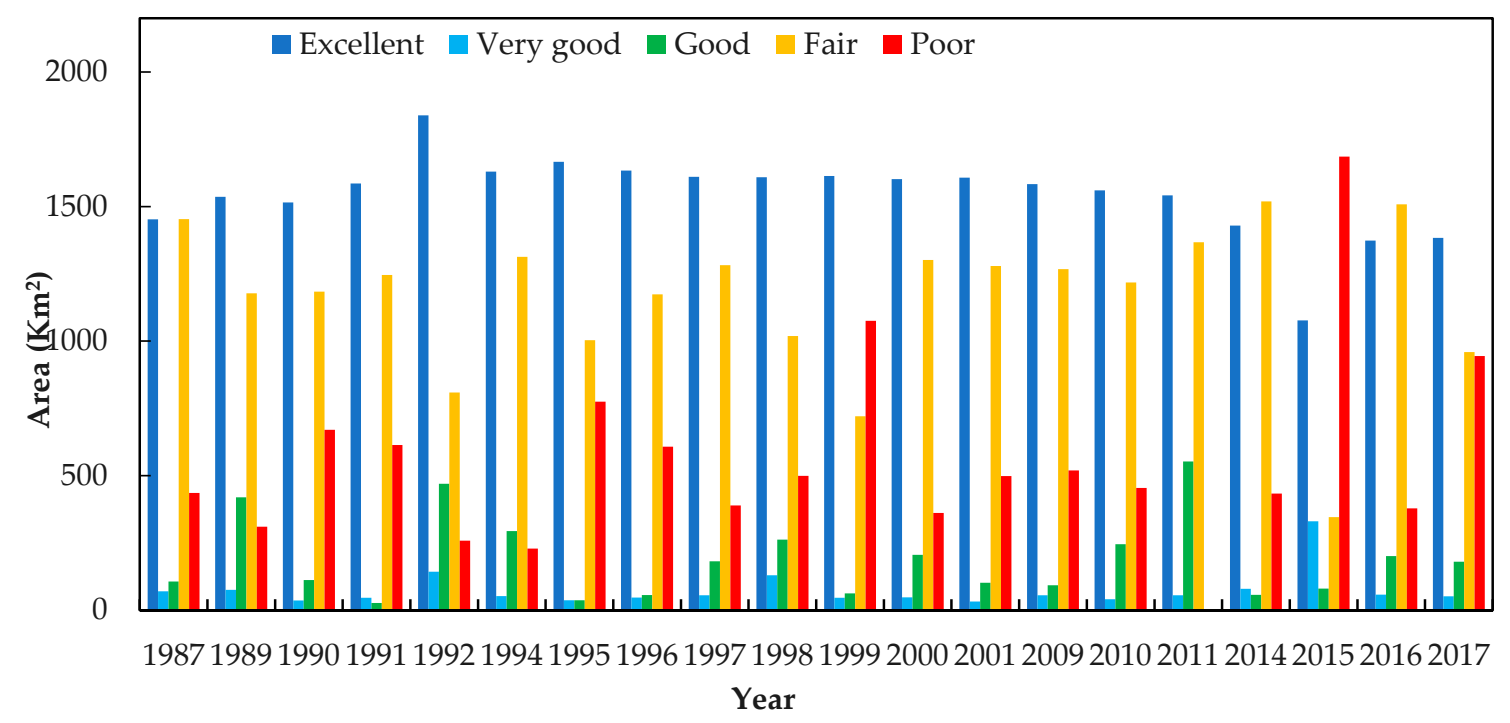

Figure 16. The areas of surface ecological conditions classes.

\section{Discussion}

Modeling surface ecological conditions is critical. Past studies in modeling surface ecological conditions have focused on modeling the impact of human activity, including population growth and urban physical expansion, on the spatiotemporal changes in surface ecological conditions $[14,15,26]$. Hence, variations in the surface ecological conditions of an area can be caused by natural and unnatural factors [7-10].

In this study, various spectral indices and methods were used to model spatiotemporal variations of the surface ecological conditions. Using a mathematical calculation between two or more reflective bands, spectral indices extract useful and effective information from the biophysical characteristics of the surface of original images. Thus, a target phenomenon is identified through spectral indices. In this study, impermeable surfaces, wetness and greenness are the three main components of information obtained from the spectral methods and indices to model the surface ecological conditions. Impermeable surfaces indicate information that includes bare soils and constructed lands, greenness indicates vegetation information, and wetness indicates water-related characteristics, soil moisture, plants, and constructed lands. In addition, LST was used as a biophysical index to assess spatiotemporal variations in surface ecological conditions. However, considering other surface characteristics, such as salinity in barren lands and vegetation health for agricultural and green space lands, can increase the accuracy of modeling the surface ecological conditions.

RSEI was developed for the modeling of SES. This was developed solely using satellite data [15] by integrating surface dryness, wetness, greenness, and heat information and showed a strong correlation with SES $[14,26]$. This index is very effective in measuring the pressures of anthropogenic activities on the environment, changes in vegetation and water and their consequences. Overall the advantages of the RSEI can be summarized as: (a) visualizable, (b) scalable, (c) comparable at different scales and (d) customizable to minimize error or variation caused by other properties in weight 
definitions $[15,26,59]$. However, using RSUSEI and CEEI to model the surface ecological conditions and comparing their results with RSEI results can be useful.

One of the weaknesses of the previous studies is the modeling of temporal changes in surface ecological conditions. In previous studies, a few limited images have been used to model the temporal variation of surface ecological conditions $[15,34,35]$. To more accurately model the spatiotemporal variations of the surface ecological conditions, Landsat images and MODIS products were used. MODIS products have a low spatial resolution but a high temporal resolution, which is more suitable for modeling the temporal variation of ecological conditions. Consequently, Landsat images were used to more accurately model spatial variations of surface ecological conditions. Additionally, using radar images, hyperspectral images and high spatial resolution (synthetic aperture radar (SAR), Hyperion, AVIRIS, Sentinel 1 and 2, Worldview-3, etc.) might have even more potential.

The modeled biophysical characteristics of the study area, based on different spectral indicators, have many spatiotemporal variations during different months of the year due to the location of the Gomishan wetland and the surface cover of Gomishan city. These temporal variations are related to the increase in human activities, the increase in saline lands, the progression and regression of the Caspian Sea water level, and the spatiotemporal changes in the water level of the Gomishan wetland [43]. The results of the land cover classification show that the vegetation cover, the size of the city, and the area of the water levels of the Gomishan wetland have changed significantly over the past years. The Gomishan wetland is connected to the Caspian Sea, which directly affects its hydrological characteristics. Temporal variations in the ecological conditions of the Gomishan wetland are higher than those of the study area and Gomishan city. Additionally, the ecological conditions of the study area are affected by the spatiotemporal changes in the water level of the Gomishan wetland. The results indicated that the effect of natural factors in changing the surface ecological conditions can be greater than the effect of natural factors. Therefore, the implementation of detailed policies and programs to control and improve the conditions of natural areas, including wetlands, can be of great importance in preventing the destruction of ecological conditions of ecosystems. In this regard, the first program could be the development of Web Geographic Information System (GIS) to monitor changes in the ecological conditions of wetlands based on satellite information.

\section{Conclusions}

Studying the spatiotemporal variations of surface biophysical characteristics and surface ecological conditions is critical for solving the challenges of environmental degradation, improving the structure and performance of ecosystems, and maintaining ecosystem services. Therefore, this study compared the degree of variation between surface ecological conditions caused by natural factors and those caused by unnatural factors. In this regard, spatiotemporal variations in the ecological conditions of Gomishan city and the Gomishan wetland have been evaluated and compared with each other. The results show that the Gomishan wetland has a lower mean LST than Gomishan city in most years. Moreover, the highest and lowest differences between various level covers are related to NDVI and albedo.

The maximum variations between the surface biophysical characteristics of the study area are related to the Caspian Sea margins. The Gomishan wetland and Gomishan city have the highest and lowest variations in biophysical characteristics, respectively. Additionally, the CV in the water lands area in the Gomishan wetland is greater than in Gomishan city. The RSEI means for the study area, Gomishan city, and the Gomishan wetland during the study period are $0.43,0.65$, and 0.29 , respectively. The ecological conditions of the study area, Gomishan city, and the Gomishan wetland changed during the study period. The surface ecological conditions of Gomishan city are worse than the ecological conditions of the study area and the Gomishan wetland. There were more changes to the surface ecological conditions of the Gomishan wetland than to those of the study area and Gomishan city. The most important factor that naturally affects the surface ecological characteristics of the Gomishan 
wetland is fluctuations in the water level of the Caspian Sea, which leads to a decrease and increase in the water level of the wetland.

Author Contributions: Conceptualization, M.K.F., N.M. and S.F.; Formal analysis, N.M., M.K.F., S.F., and S.K.A.; Funding acquisition, S.K.A. and S.Q.; Investigation, N.M., S.F. and M.K.F.; Methodology, M.K.F., N.M., S.F., S.K.A. and S.Q.; Project administration, S.K.A.; Software, N.M. and M.K.F.; Supervision, S.Q. and S.K.A.; Visualization, N.M., M.K.F., S.F. and S.Q.; Writing—original draft, M.K.F., N.M. and S.F.; Writing-review \& editing, S.Q., S.K.A., M.H., A.A.K., S.H. and M.K. All authors have read and agreed to the published version of the manuscript.

Funding: This study was supported by the Iran National Science Foundation (Grant No. 96003646), Russian Foundation for Basic Research (Grant No. 17-55-560006) and Agrohydrology Research Group of Tarbiat Modares University (Grant No. IG-39713).

Acknowledgments: The authors thank anonymous reviewers for their constructive comments and suggestions which helped to improve the manuscript. The authors would also like to acknowledge the Iran National Science Foundation, Russian Foundation for Basic Research and Agrohydrology Research Group of Tarbiat Modares University for its support in conducting this research. We acknowledge support by the Open Access Publication Fund of Humboldt-Universität zu Berlin.

Conflicts of Interest: The authors declare no conflict of interest.

\section{References}

1. He, Y.; Xie, H. Exploring the spatiotemporal changes of ecological carrying capacity for regional sustainable development based on GIS: A case study of Nanchang City. Technol. Forecast. Soc. Chang. 2019, 148, 119720. [CrossRef]

2. Hou, K.; Tao, W.; Wang, L.; Li, X. Study on hierarchical transformation mechanisms of regional ecological vulnerability and its applicability. Ecol. Indic. 2020, 114, 106343. [CrossRef]

3. Yang, Y.; Meng, G. A bibliometric analysis of comparative research on the evolution of international and Chinese ecological footprint research hotspots and frontiers since 2000. Ecol. Indic. 2019, 102, 650-665. [CrossRef]

4. Szigeti, C.; Toth, G.; Szabo, D.R. Decoupling-shifts in ecological footprint intensity of nations in the last decade. Ecol. Indic. 2017, 72, 111-117. [CrossRef]

5. Mijani, N.; Alavipanah, S.K.; Firozjaei, M.K.; Arsanjani, J.J.; Hamzeh, S.; Weng, Q. Modeling outdoor thermal comfort using satellite imagery: A principle component analysis-based approach. Ecol. Indic. 2020, 117, 106555. [CrossRef]

6. Wang, R.; Li, F.; Hu, D.; Li, B.L. Understanding eco-complexity: Social-economic-natural complex ecosystem approach. Ecol. Complex. 2011, 8, 15-29. [CrossRef]

7. Larson, K.L.; Nelson, K.C.; Samples, S.; Hall, S.; Bettez, N.; Cavender-Bares, J.; Groffman, P.; Grove, M.; Heffernan, J.; Hobbie, S.E. Ecosystem services in managing residential landscapes: Priorities, value dimensions, and cross-regional patterns. Urban. Ecosyst. 2016, 19, 95-113. [CrossRef]

8. $\mathrm{Xu}, \mathrm{C}$.; Jiang, W.; Huang, Q.; Wang, Y. Ecosystem services response to rural-urban transitions in coastal and island cities: A comparison between Shenzhen and Hong Kong, China. J. Clean. Prod. 2020, 121033. [CrossRef]

9. Varin, M.; Theau, J.; Fournier, R.A. Mapping ecosystem services provided by wetlands at multiple spatiotemporal scales: A case study in Quebec, Canada. J. Environ. Manag. 2019, 246, 334-344. [CrossRef]

10. Yuan, Y.; Wu, S.; Yu, Y.; Tong, G.; Mo, L.; Yan, D.; Li, F. Spatiotemporal interaction between ecosystem services and urbanization: Case study of Nanjing City, China. Ecol. Indic. 2018, 95, 917-929. [CrossRef]

11. Liu, Q.; Wu, J.; Li, L. Ecological environment monitoring for sustainable development goals in the Belt and Road region. J. Remote Sens. 2018, 22, 686-708.

12. Willis, K.S. Remote sensing change detection for ecological monitoring in United States protected areas. Biol. Conserv. 2015, 182, 233-242. [CrossRef]

13. Weng, Q. Thermal infrared remote sensing for urban climate and environmental studies: Methods, applications, and trends. ISPRS J. Photogramm. Remote Sens. 2009, 64, 335-344. [CrossRef]

14. Firozjaei, M.K.; Fathololoumi, S.; Weng, Q.; Kiavarz, M.; Alavipanah, S.K. Remotely Sensed Urban Surface Ecological Index (RSUSEI): An Analytical Framework for Assessing the Surface Ecological Status in Urban Environments. Remote Sens. 2020, 12, 2029. [CrossRef] 
15. $\mathrm{Hu}, \mathrm{X} . ; \mathrm{Xu}, \mathrm{H}$. A new remote sensing index for assessing the spatial heterogeneity in urban ecological quality: A case from Fuzhou City, China. Ecol. Indic. 2018, 89, 11-21. [CrossRef]

16. de Araujo Barbosa, C.C.; Atkinson, P.M.; Dearing, J.A. Remote sensing of ecosystem services: A systematic review. Ecol. Indic. 2015, 52, 430-443. [CrossRef]

17. Reza, M.I.H.; Abdullah, S.A. Regional Index of Ecological Integrity: A need for sustainable management of natural resources. Ecol. Indic. 2011, 11, 220-229. [CrossRef]

18. Kennedy, R.E.; Andréfouët, S.; Cohen, W.B.; Gómez, C.; Griffiths, P.; Hais, M.; Healey, S.P.; Helmer, E.H.; Hostert, P.; Lyons, M.B. Bringing an ecological view of change to Landsat-based remote sensing. Front. Ecol. Environ. 2014, 12, 339-346. [CrossRef]

19. Firozjaei, M.K.; Weng, Q.; Zhao, C.; Kiavarz, M.; Lu, L.; Alavipanah, S.K. Surface anthropogenic heat islands in six megacities: An assessment based on a triple-source surface energy balance model. Remote Sens. Environ. 2020, 242, 111751. [CrossRef]

20. Wu, J.; Wang, X.; Zhong, B.; Yang, A.; Jue, K.; Wu, J.; Zhang, L.; Xu, W.; Wu, S.; Zhang, N. Ecological environment assessment for Greater Mekong Subregion based on Pressure-State-Response framework by remote sensing. Ecol. Indic. 2020, 117, 106521. [CrossRef]

21. White, D.C.; Lewis, M.M.; Green, G.; Gotch, T.B. A generalizable NDVI-based wetland delineation indicator for remote monitoring of groundwater flows in the Australian Great Artesian Basin. Ecol. Indic. 2016, 60, 1309-1320. [CrossRef]

22. Coutts, A.M.; Harris, R.J.; Phan, T.; Livesley, S.J.; Williams, N.S.; Tapper, N.J. Thermal infrared remote sensing of urban heat: Hotspots, vegetation, and an assessment of techniques for use in urban planning. Remote Sens. Environ. 2016, 186, 637-651. [CrossRef]

23. Ochoa-Gaona, S.; Kampichler, C.; De Jong, B.; Hernández, S.; Geissen, V.; Huerta, E. A multi-criterion index for the evaluation of local tropical forest conditions in Mexico. For. Ecol. Manag. 2010, 260, 618-627. [CrossRef]

24. Nichol, J. An emissivity modulation method for spatial enhancement of thermal satellite images in urban heat island analysis. Photogramm. Eng. Remote Sens. 2009, 75, 547-556. [CrossRef]

25. Yue, H.; Liu, Y.; Li, Y.; Lu, Y. Eco-environmental quality assessment in China's 35 major cities based on remote sensing ecological index. IEEE Access 2019, 7, 51295-51311. [CrossRef]

26. Xu, H.; Wang, M.; Shi, T.; Guan, H.; Fang, C.; Lin, Z. Prediction of ecological effects of potential population and impervious surface increases using a remote sensing based ecological index (RSEI). Ecol. Indic. 2018, 93, 730-740. [CrossRef]

27. Zhang, J.; Zhu, Y.; Fan, F. Mapping and evaluation of landscape ecological status using geographic indices extracted from remote sensing imagery of the Pearl River Delta, China, between 1998 and 2008. Environ. Earth Sci. 2016, 75, 327. [CrossRef]

28. Li, J.; Song, C.; Cao, L.; Zhu, F.; Meng, X.; Wu, J. Impacts of landscape structure on surface urban heat islands: A case study of Shanghai, China. Remote Sens. Environ. 2011, 115, 3249-3263. [CrossRef]

29. Buyantuyev, A.; Wu, J. Urban heat islands and landscape heterogeneity: Linking spatiotemporal variations in surface temperatures to land-cover and socioeconomic patterns. Landsc. Ecol. 2010, 25, 17-33. [CrossRef]

30. Fu, Y.; Shi, X.; He, J.; Yuan, Y.; Qu, L. Identification and optimization strategy of county ecological security pattern: A case study in the Loess Plateau, China. Ecol. Indic. 2020, 112, 106030. [CrossRef]

31. Ouyang, Z.; Wang, Q.; Zheng, H.; Zhang, F.; Hou, P. National ecosystem survey and assessment of China (2000-2010). Bull. Chin. Acad. Sci. 2014, 29, 462-466.

32. Guan, Q.; Hao, J.; Ren, G.; Li, M.; Chen, A.; Duan, W.; Chen, H. Ecological indexes for the analysis of the spatial-temporal characteristics of ecosystem service supply and demand: A case study of the major grain-producing regions in Quzhou, China. Ecol. Indic. 2020, 108, 105748. [CrossRef]

33. Shan, W.; Jin, X.; Ren, J.; Wang, Y.; Xu, Z.; Fan, Y.; Gu, Z.; Hong, C.; Lin, J.; Zhou, Y. Ecological environment quality assessment based on remote sensing data for land consolidation. J. Clean. Prod. 2019, 239, 118126. [CrossRef]

34. Yang, C.; Zhang, C.; Li, Q.; Liu, H.; Gao, W.; Shi, T.; Liu, X.; Wu, G. Rapid urbanization and policy variation greatly drive ecological quality evolution in Guangdong-Hong Kong-Macau Greater Bay Area of China: A remote sensing perspective. Ecol. Indic. 2020, 115, 106373. [CrossRef] 
35. Chen, X.; Li, F.; Li, X.; Hu, Y.; Wang, Y. Mapping ecological space quality changes for ecological management: A case study in the Pearl River Delta urban agglomeration, China. J. Environ. Manag. 2020, 267, 110658. [CrossRef]

36. Shen, G.; Yang, X.; Jin, Y.; Xu, B.; Zhou, Q. Remote sensing and evaluation of the wetland ecological degradation process of the Zoige Plateau Wetland in China. Ecol. Indic. 2019, 104, 48-58. [CrossRef]

37. Eid, A.N.M.; Olatubara, C.; Ewemoje, T.; El-Hennawy, M.T.; Farouk, H. Inland wetland time-series digital change detection based on SAVI and NDWI indecies: Wadi El-Rayan lakes, Egypt. Remote Sens. Appl. Soc. Environ. 2020, 19, 100347. [CrossRef]

38. Rapinel, S.; Fabre, E.; Dufour, S.; Arvor, D.; Mony, C.; Hubert-Moy, L. Mapping potential, existing and efficient wetlands using free remote sensing data. J. Environ. Manag. 2019, 247, 829-839. [CrossRef]

39. Singh, S.; Bhardwaj, A.; Verma, V. Remote sensing and GIS based analysis of temporal land use/land cover and water quality changes in Harike wetland ecosystem, Punjab, India. J. Environ. Manag. 2020, 262, 110355. [CrossRef]

40. Orimoloye, I.R.; Mazinyo, S.P.; Kalumba, A.; Nel, W.; Adigun, A.I.; Ololade, O.O. Wetland shift monitoring using remote sensing and GIS techniques: Landscape dynamics and its implications on Isimangaliso Wetland Park, South Africa. Earth Sci. Inform. 2019, 12, 553-563. [CrossRef]

41. Alavipanah, S.; Konyushkova, M.; Hamzeh, S.; Kakroodi, A.; Heidari, A.; Firozjaei, M.; Mijani, N. Characterizing Spatial and Temporal Trends of Soil and Surface Properties Changes in AN Area with Urban, Bare Soil and Wetland Covers: A 30-YEAR Case Study in Gomishan, Iran. Int. Arch. Photogramm. Remote Sens. Spat. Inf. Sci. 2019, 42, 51-56. [CrossRef]

42. Emberger, L. Sur une formule climatique et ses applications en botanique. La Météorol. 1932, 92, 1-10.

43. Jeihouni, M.; Kakroodi, A.; Hamzeh, S. Monitoring shallow coastal environment using Landsat/altimetry data under rapid sea-level change. Estuar. Coast. Shelf Sci. 2019, 224, 260-271. [CrossRef]

44. Bodart, C.; Eva, H.; Beuchle, R.; Raši, R.; Simonetti, D.; Stibig, H.-J.; Brink, A.; Lindquist, E.; Achard, F. Pre-processing of a sample of multi-scene and multi-date Landsat imagery used to monitor forest cover changes over the tropics. ISPRS J. Photogramm. Remote Sens. 2011, 66, 555-563. [CrossRef]

45. Bruce, C.M.; Hilbert, D.W. Pre-Processing Methodology for Application to Landsat TM/ETM+ Imagery of the Wet Tropics; Rainforest CRC: Cairns, Australia, 2006.

46. Phiri, D.; Morgenroth, J.; Xu, C.; Hermosilla, T. Effects of pre-processing methods on Landsat OLI-8 land cover classification using OBIA and random forests classifier. Int. J. Appl. Earth Obs. Geoinf. 2018, 73, 170-178. [CrossRef]

47. Tucker, C.J. Red and photographic infrared linear combinations for monitoring vegetation. Remote Sens. Environ. 1979, 8, 127-150. [CrossRef]

48. Allbed, A.; Kumar, L. Soil salinity mapping and monitoring in arid and semi-arid regions using remote sensing technology: A review. Adv. Remote Sens. 2013, 2013. [CrossRef]

49. Zha, Y.; Gao, J.; Ni, S. Use of normalized difference built-up index in automatically mapping urban areas from TM imagery. Int. J. Remote Sens. 2003, 24, 583-594. [CrossRef]

50. Gao, B.C. NDWI-A normalized difference water index for remote sensing of vegetation liquid water from space. Remote Sens. Environ. 1996, 58, 257-266. [CrossRef]

51. Taleghani, M. The impact of increasing urban surface albedo on outdoor summer thermal comfort within a university campus. Urban. Clim. 2018, 24, 175-184. [CrossRef]

52. Liu, Q.; Liu, G.; Huang, C.; Liu, S.; Zhao, J. A tasseled cap transformation for Landsat 8 OLI TOA reflectance images. In Proceedings of the Geoscience and Remote Sensing Symposium (IGARSS) 2014 IEEE International, Quebec, QC, Canada, 13-18 July 2014; pp. 541-544.

53. Liu, Q.; Liu, G.; Huang, C.; Xie, C. Comparison of tasselled cap transformations based on the selective bands of Landsat 8 OLI TOA reflectance images. Int. J. Remote Sens. 2015, 36, 417-441. [CrossRef]

54. Jiménez-Muñoz, J.C.; Sobrino, J.A. A generalized single-channel method for retrieving land surface temperature from remote sensing data. J. Geophys. Res. Atmos. 2003, 108, 4688. [CrossRef]

55. Firozjaei, M.K.; Kiavarz, M.; Alavipanah, S.K.; Lakes, T.; Qureshi, S. Monitoring and forecasting heat island intensity through multi-temporal image analysis and cellular automata-Markov chain modelling: A case of Babol city, Iran. Ecol. Indic. 2018, 91, 155-170. [CrossRef]

56. Weng, Q.; Firozjaei, M.K.; Sedighi, A.; Kiavarz, M.; Alavipanah, S.K. Statistical analysis of surface urban heat island intensity variations: A case study of Babol city, Iran. GISci. Remote Sens. 2018, 1-29. [CrossRef] 
57. Otukei, J.R.; Blaschke, T. Land cover change assessment using decision trees, support vector machines and maximum likelihood classification algorithms. Int. J. Appl. Earth Obs. Geoinf. 2010, 12, S27-S31. [CrossRef]

58. Moghaddam, M.H.R.; Sedighi, A.; Fasihi, S.; Firozjaei, M.K. Effect of environmental policies in combating aeolian desertification over Sejzy Plain of Iran. Aeolian Res. 2018, 35, 19-28. [CrossRef]

59. Xu, H.; Wang, Y.; Guan, H.; Shi, T.; Hu, X. Detecting Ecological Changes with a Remote Sensing Based Ecological Index (RSEI) Produced Time Series and Change Vector Analysis. Remote Sens. 2019, 11, 2345. [CrossRef]

(C) 2020 by the authors. Licensee MDPI, Basel, Switzerland. This article is an open access article distributed under the terms and conditions of the Creative Commons Attribution (CC BY) license (http://creativecommons.org/licenses/by/4.0/). 